\title{
La iconografía del Arcángel San Miguel y su simbolismo político en las monedas del final del Medievo en la Europa Occidental
}

\author{
Coin iconography of Archangel St. Michael and its political \\ symbolism in Western Europe during the Late Middle Ages
}

\author{
José María de FRANCISCO OLMOS
}

\author{
Universidad Complutense de Madrid \\ Departamento de Ciencias y Técnicas Historiográficas \\ josemafr@pdi.ucm.es
}

Recibido: 08/12/2012

Aprobado: 15/12/2012

Resumen: En este trabajo se va a repasar la importancia de la iconografía del Arcángel San Miguel en las acuñaciones monetarias del final del medievo. Partiremos de su presencia en la moneda bizantina desde el siglo XI, explicando el porqué de su aparición en este Imperio, y cómo en Occidente eran muy importantes sus santuarios y veneración. Sin embargo, no aparece en las monedas hasta mediados del siglo XIV, en la Francia de los primeros Valois y el inicio de la Guerra de los Cien Años, marcando ya una carga política muy importante, que no tendrá continuidad hasta la segunda mitad del siglo XV, cuando en Inglaterra, Francia y Nápoles, en períodos de tiempo muy cercanos, su imagen va a dominar algunas series monetarias con una iconografía prácticamente igual, donde los monarcas de estos territorios buscan justificar su poder y el respaldo divino que les ha proporcionado la victoria sobre las rebeliones organizadas por sus nobles, con la analogía de la victoria del Arcángel sobre los demonios rebelados contra Dios.

Palabras Clave: Arcángel San Miguel, Iconografía monetaria, Bizancio, Francia, Inglaterra, Nápoles.

\begin{abstract}
This paper reviews the importance of the iconography of Archangel St. Michael in coin mintages in the late Middle Ages. Beginning by its presence in the Byzantine coins in the eleventh century, we explain the reasons of the Archangel's appearance in this Empire, and the importance of its sanctuaries and veneration in Occident. It did not appear on coins, however, until mid fourteenth century in France, in the French Valois dynasty at the beginning of The Hundred Years' War, setting an important political impact. Not until the second half of the fifteenth century did this impact resume, at that moment in England, France and Naples the Archangel's image dominated a few coinage series with a very similar iconography. The monarchs of those countries felt the need to justify their power and decided to use the divine endorsement which contributed to their victory over the rebellions organised by their nobility, drawing upon the analogy of the victory of the Archangel over the rebel demons that rose against God.
\end{abstract}

Key Words: Archangel St.Michael, coin iconography, Byzantium, France, England, Naples

Sumario: 1. La Numismática como fuente histórica. 2. La iconografía cristiana en la moneda tardorromana y bizantina. 3. El arcángel San Miguel en la iconografía monetaria bizantina. 4. El arcángel San Miguel en Occidente. 5. El arcángel San Miguel en la iconografía monetaria de Occidente. 6. Conclusiones. Fuentes y Bibliografía. 


\section{La numismática como fuente histórica}

La moneda ha sido siempre un elemento de propaganda política de primer orden al servicio del que gobierna, en virtud del monopolio emisor del que goza el poder estatal. Las piezas monetarias, que pasan de mano en mano en multitud de intercambios, son el mejor medio para difundir determinadas ideas de interés para el poder político. De hecho, a lo largo de la Historia lo primero que ha realizado un soberano al subir al Trono ha sido emitir moneda a su nombre, pues es esta la forma más efectiva de ratificar su poder. La emisión de moneda como monopolio del Estado permite el conocimiento objetivo de la situación política de una determinada época histórica y puede reforzar el obtenido a través de otras fuentes.

Asimismo, aporta datos sobre acontecimientos históricos concretos, sobre elementos de uso cotidiano, como armas, instrumentos musicales, barcos, etc. El conocimiento de las monedas es de tremenda utilidad en este aspecto, partiendo de la base de que el abridor de cuños no suele inventar cuando representa objetos reales, aunque es cierto que en algunas ocasiones sintetiza o simplifica, forzado por la mediatización que la pequeñez del cospel le impone. Por todo ello los actuales estudios numismáticos no se limitan a pesar, medir y ordenar las distintas piezas, o a catalogarlas sin más, sino que el historiador de la moneda no puede obviar los aspectos políticos, sociales, económicos, comerciales, religiosos, artísticos, etc., que rodean la moneda y explican las características intrínsecas y extrínsecas de las mismas. La moneda debe estudiarse en todas sus vertientes, como documento vivo de la historia, de hecho probablemente el más excepcional de todos, ya que en sí reúne numerosa información de todos los campos de la sociedad que la crea. Veamos ahora algunos de los aspectos de los que informa el documento numismático:

a) Material de la moneda: La moneda ha sido tradicionalmente de metal, que tenía en sí mismo un valor intrínseco, que podía ser prácticamente el mismo que su valor de circulación (como en el mundo griego), o bien menor, dejando al poder emisor un beneficio por su producción. Si estos valores intrínseco y de circulación se separan mucho, se llega a la llamada moneda fiduciaria, la que se fue imponiendo en todo el mundo desde la época de la República Romana, siendo la que actualmente domina en todo el mundo.

En la moneda fiduciaria el valor de la misma no lo da el valor del material utilizado en su realización, sino el que el Estado impone, siendo admitido únicamente por convenio. Si el Estado quiebra su moneda, carece de valor. Como ejemplo de esto pueden citarse dos casos: la moneda emitida por los Estados Confederados de América y por la II República Española; al concluir los conflictos civiles en ambos países y ser la parte derrotada, su moneda se convirtió en inservible y sin ningún valor, al desaparecer el Poder emisor que la respaldaba. Desde hace unos siglos, el papel ha ido poco a poco ganando terreno al metal como material preferente de las monedas, pero esto no varía en nada lo expuesto anteriormente. Ocasionalmente se van a fabricar monedas de otros materiales: son monedas obsidionales, de urgencia, cuya emisión se debe a circunstancias políticas o económicas muy concretas y especiales, y por tanto nos ofrecen también una 
importante información sobre el momento concreto por el que pasa la sociedad a la que sirven.

b) La Calidad: Durante la mayor parte del tiempo en que ha existido la economía monetaria la salud de dicha economía ha sido medida por la calidad de su moneda, es decir, la relación entre la cantidad de metal que la componía (y, por tanto, de que se ajustara a la normativa legal de fabricación) y su contenido real, muchas veces variado por los gobernantes sin informar de ello y sin variar su valor oficial de circulación.

Actualmente, en especial gracias a los análisis metalográficos, podemos estudiar la composición de las monedas metálicas y hacer unas tablas estadísticas sobre las diferentes aleaciones metálicas utilizadas en su realización, comparando la cantidad de metal noble utilizado y cómo este subía o bajaba según las circunstancias políticas y económicas de la sociedad. Son especialmente destacables los estudios hechos sobre este asunto en la moneda romana imperial, por ejemplo, sobre la depreciación constante de la calidad de monedas como el áureo o el antoniano de plata durante la crisis del siglo III, o bien sobre la moneda visigoda de oro, donde los reinados tranquilos muestran un alto contenido de oro en la misma (Leovigildo, Recesvinto), mientras en otros se reduce drásticamente por los problemas internos. Igualmente, y gracias a dichos métodos, se puede estudiar cómo los gobernantes de todos los períodos han usado la moneda, preferentemente devaluándola ("quebrándola"), para conseguir sanear momentáneamente la Hacienda, lo que va a provocar siempre una consecuencia inevitable, la inflación. Como ejemplo de esto podemos citar en Castilla los muy conocidos manejos monetarios de Alfonso X o Felipe IV.

c) Patrón Ponderal: Nos pone en contacto con las pesas y medidas de cada sociedad, nos informa de cómo se articulaba y cómo contaba, y por tanto de cuál era la relación de cada moneda dentro de su sistema, con múltiplos y divisores de la unidad.

Tradicionalmente se habla de dos grandes sistemas: el de base 12, tomado del sexagesimal de origen babilonio, que ha subsistido hasta el siglo XX (Gran Bretaña lo abandonó en 1971, cuando entró oficialmente en la Comunidad Económica Europea); y el de base 10, que los árabes adoptaron en el siglo VIII d.C., tardando diez siglos en ser aceptado por Europa, siendo la Revolución Francesa la que lo asimiló, y poco a poco se extendió por todos los países durante el siglo XIX y XX. También debemos estudiar la relación entre las monedas de distintos metales en una misma economía (la ratio), en especial entre el oro y la plata, ya que variaba dependiendo de su abundancia o escasez en determinado lugar, con lo que su valor de cambio era distinto en cada lugar.

d) Origen y Control del Material: Muy ligado al tema anterior, gracias a las nuevas tecnologías, podemos saber con precisión el origen del metal del que están hechas las monedas. Este dato no es una simple curiosidad, ya que nos acerca al tema del tráfico mercantil y de las relaciones de poder, quién controlaba las minas suministradoras de material, eran públicas o privadas, qué contrapartidas se exigían por el aprovisionamiento, etc. 
e) Aleaciones y Técnicas: La realización física de la moneda nos pone en contacto con el fascinante mundo de la tecnología en todas sus variantes. Cómo se realizaban el cospel y los tipos monetarios en el caso de la moneda metálica, o bien cuáles eran las características especiales del papel destinado a las Fábricas de Moneda, sus signos y marcas de fábrica, sus contraseñas, sus garantías contra la falsificación. Todo esto nos lleva a estudiar tanto los distintos materiales utilizados para la realización de la moneda como a los hombres que las realizaban. Personajes unas veces desconocidos, como los primeros entalladores de piedras duras que trabajaron en el mundo griego, otras veces grandes artistas que firmaban sus obras (Kymon, Evainetos, etc...), o bien familias que durante generaciones se dedicaron al grabado, siendo ensayadores de las fábricas, pasando el oficio de padre a hijos.

En definitiva la moneda nos ofrece un documento de primera mano para estudiar los avances de la metalurgia, de la técnica de la fundición, de la acuñación, del grabado, así como del desarrollo de la tecnología de la maquinaría destinada a su producción (molino, volante, prensa...), y también la organización y funcionamiento de las cecas.

f) Circulación: Es también un punto muy importante, ya que la circulación monetaria nos da la vida (marco cronológico de uso de una determinada moneda) y la influencia (marco geográfico en el que fue usada) de cada especie monetaria. Nos informa tanto del poder de la economía que la emitió como de su poder político, así como de las relaciones entre diversas sociedades, los tipos de cambio utilizados y la posible "colonización" económica a las que se ven sometidas las sociedades.

g) Arte: La moneda es reflejo de la sociedad que la emite, y los tipos representados en ella se realizan siguiendo unas determinadas corrientes artísticas; por tanto, la moneda también nos informa de qué corrientes artísticas dominan (o bien son las consideradas oficiales) en un momento determinado. El caso más significativo de la relación del arte con el estudio de la Numismática como documento es el de la moneda griega, que es clasificada temporalmente siguiendo criterios artísticos.

h) Estudio de los Tipos y Leyendas Monetales: Nos pone en contacto con la mentalidad de la sociedad a la que sirve la moneda, aportándonos numerosos datos, como pueden ser:

- El tipo de sistema político y organización social. Quién domina el poder, entre quienes se reparte, cómo se accede a él.

- La forma del Estado y sus características.

- Quién o quiénes son los gobernantes.

- Cuál es el origen de su poder y su relación con los gobernados.

- Las creencias religiosas: divinidades, cultos, miembros del panteón, jerarquías, así como la relación de la divinidad con el poder.

- Los mitos y leyendas de cada sociedad.

- El ceremonial, tanto político (elecciones, tomas de posesión...) como religioso (procesiones, ofrendas...), y también cívico o lúdico. En las monedas podemos ver su organización y desarrollo.

- Los posibles conflictos internos (varias facciones enfrentadas por alcanzar el poder, rebeliones, etc...) o externos (reivindicaciones territoriales). 
- La escala de valores de la sociedad (o del poder establecido). Es muy interesante estudiar qué personajes o hechos de relieve se representan en los distintos valores monetarios, ya que nos informan de una determinada tendencia encauzada desde el poder.

- La Flora y Fauna del territorio que controlan, a veces como referencia religiosa (símbolos totémicos), otras como homenaje y a veces indicando que son la principal base de su economía. En este apartado podemos incluir también las referencias a animales mitológicos.

- Historia del Arte, que nos da noticias no solo de las tendencias del momento al realizar de una determinada manera los tipos y leyendas, sino también por los tipos en sí, que nos informan de determinadas obras de arte (arquitectura, pintura y escultura), o bien obras públicas, que solo conocemos porque se han representado en algunas monedas, no teniendo más datos de ellas; o bien cuáles son las obras emblemáticas de una sociedad, que las elige para aparecer en sus monedas como representación de la cultura nacional.

- Vida cotidiana: en la moneda aparecen los personajes más variados, y en las actitudes más diversas. Gracias a ellos podemos conocer la moda de la época (peinados, vestidos, calzado, sombreros...), el mobiliario, los juegos, los instrumentos musicales, el trabajo diario, las estaciones del año...

- Vida militar: uno de los elementos que más aparecen en las monedas es la milicia. Gracias a su estudio podemos ver la evolución del armamento, tanto personal como de asedio, transportes, etc... Además podemos estudiar uniformes, intendencia, organización...

- Historia de la Tecnología: También aparecen en las monedas muchos elementos de la vida diaria, cotidiana, que nos ofrecen información sobre los medios de transporte dominantes en cada momento, los instrumentos utilizados para realizar las más diversas tareas (tanto agrícolas como industriales), incluso aparecen representados las técnicas e instrumentos utilizados para fabricar la moneda.

i) La Legislación: si hemos dicho que la moneda se caracteriza por ser regulada y controlada por el Estado, entonces el estudio del corpus legislativo referente a la moneda debe también formar parte de los datos que nos ofrecen las piezas. La ley de emisión, la ley de fabricación, las leyes contra el fraude y la falsificación, las que regulaban de forma específica el funcionamiento de las cecas, etc... nos informarán del grado de complejidad de la maquinaria monetaria y del saneamiento de la economía de su sociedad.

Y así podríamos continuar casi hasta el infinito. Este es el objeto de estudio de la Numismática y su campo de acción, centrándose especialmente en sus dos vertientes principales, la económica y la de sus relaciones con el poder estatal que la emite, y es su elemento publicitario más importante 


\title{
2. La iconografía cristiana en la moneda tardorromana y bizantina
}

Desde época de Constantino el Grande comienzan a aparecer en las monedas algunos símbolos relacionados con el Cristianismo ${ }^{1}$, en principio menores, tales como un pequeño crismón colocado en algún lugar no central de la moneda, pero poco a poco este símbolo irá adquiriendo mayor rango, como vemos en la moneda realizada en Constantinopla (Fig. 1), donde se coloca sobre el estandarte imperial como símbolo de victoria sobre el enemigo (serpiente). Poco después el crismón se incorporará de forma definitiva al nuevo estandarte imperial, el Lábaro, como vemos en fechas tan tempranas como el segundo tercio del siglo IV en este medallón de plata de Constante (Fig. 2).
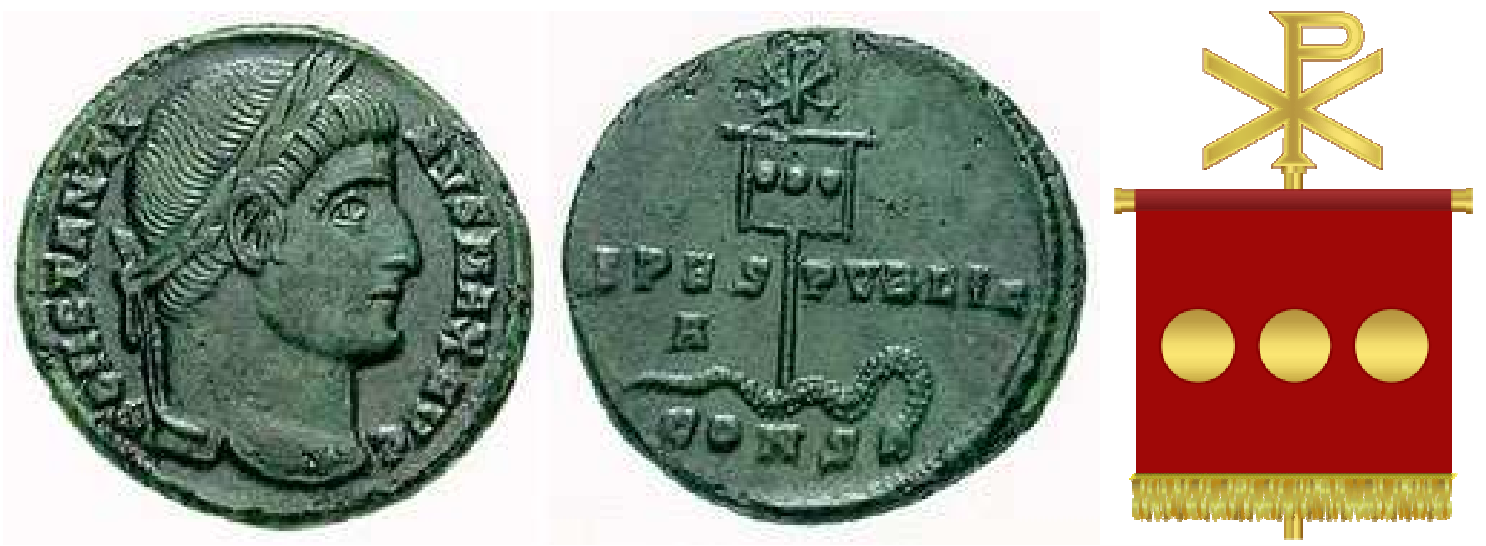

Fig. 1. RIC VII, Constantinopla 19
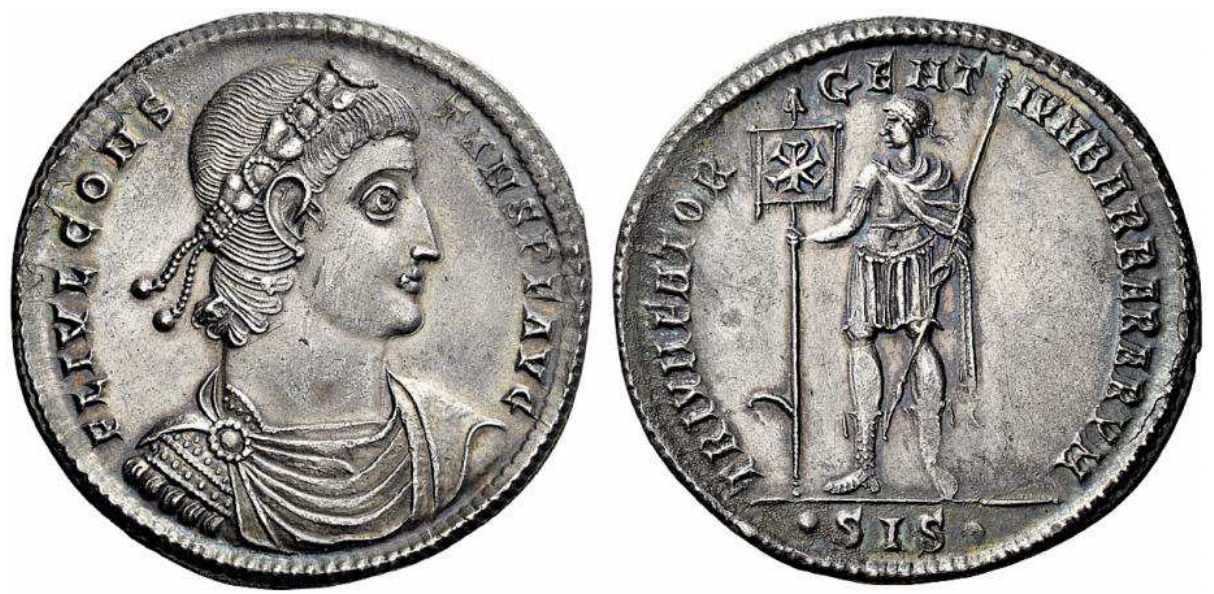

Fig. 2. RIC VIII, Siscia 148

\begin{abstract}
${ }^{1}$ No vamos a tratar aquí este interesante tema, sino que trazaremos un simple resumen que nos introduzca en el tema del estudio, aunque recomendamos para estos primeros momentos el tradicional trabajo de Patrick BRUNN, "The Christian Signs on the Coins of Constantine", Arctos; acta philologica fennica, vol.3 (1962) pp.5-35, y su continuación "The Victorious Signs of Constantine: A Reappraisal." The Numismatic Chronicle 157 (1997), pp. 41-59; así como los de Rachelle LONGTIN, "Constantine and Christianity: The Numismatic Evidence", The Journal of the Classical \& Medieval Numismatic Society 1 (September 2000), pp. 5-27; Philip KIERNAN, "A Study on the Religious Propaganda of Ancient Coin Reverse Types, A.D. 313-337", The Journal of the Classical \& Medieval Numismatic Society 2 (June 2001), pp. 92-96; y Mark DunNING, "First Christian Symbols on Roman Imperial Coins" The Celator 17, (December 2003), pp. 6-26.
\end{abstract}


A partir de este momento los símbolos cristianos irán tomando más importancia. Así en el 350, un año crítico en lo político, el usurpador Magnencio, coloca como tipo principal de algunos de sus bronces el Crismón (Fig. 3), mostrando su defensa de la fe ortodoxa en Occidente frente al cada vez mayor influjo del arrianismo en Oriente, y su oponente Vetranio, que apoyaba a la familia de Constantino, reivindica el papel de este en la introducción de la nueva fe acuñando unos bronces con la frase "hoc signo victor eris" (Fig. 4), que son el más antiguo documento oficial con la legendaria frase presente en la batalla del Puente Milvio $^{2}$.
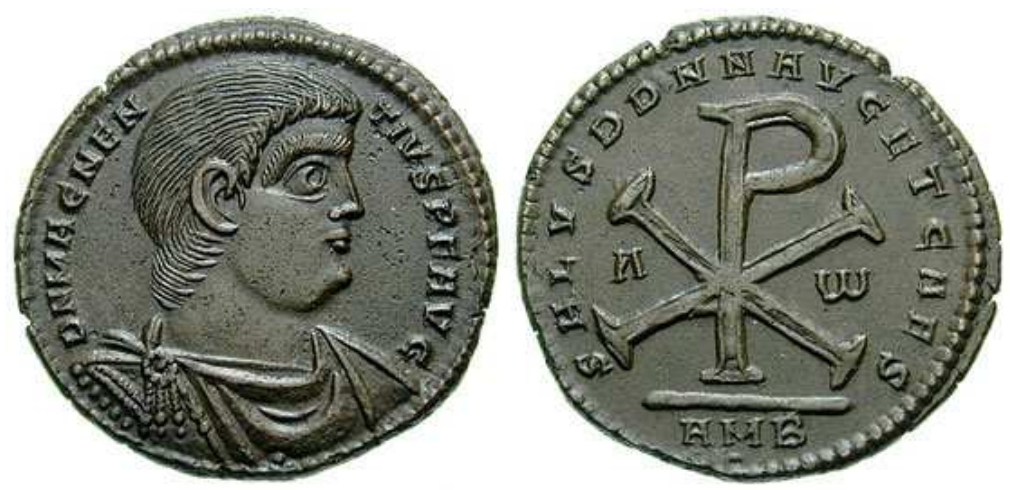

Fig. 3. RIC VIII, Amiens, 34
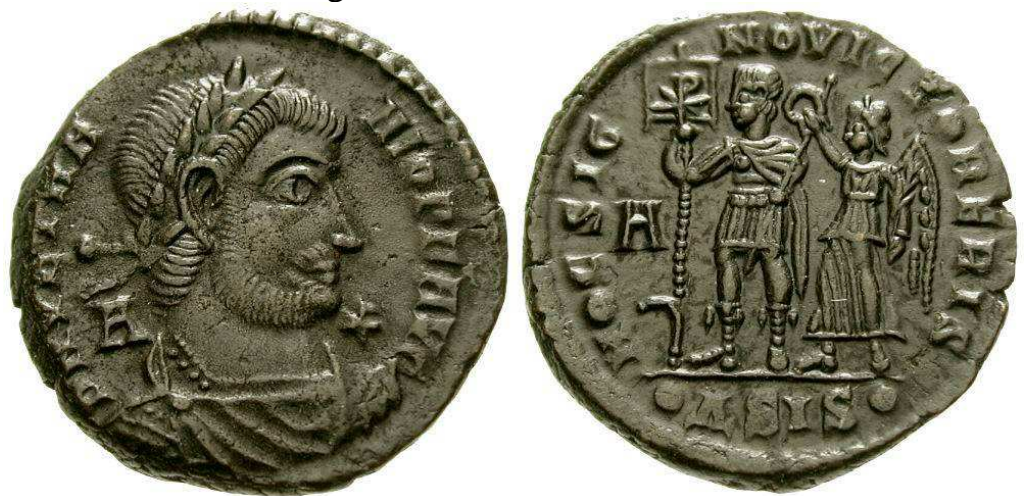

Fig. 4. RIC VIII, Siscia, 287

Poco después (finales del siglo IV) empezará a aparecer otro signo de legitimación divina, la llamada "Manus Dei", que saliendo de la parte superior de la moneda señala al emperador como el elegido por la Providencia divina. Recordemos que la idea central de la nueva doctrina política era que el emperador era la "imagen" del rey celeste, cuyo reino debe realizarse sobre la tierra. El emperador se convierte así en vicario de Dios, en su "elegido" para llevar a cabo la misión de realizar su Reino en la tierra, gracias a que como tal participa, por efluvio divino, de las virtudes celestiales. De esta manera se articula el Imperio romano a la Providencia Divina y se establece la ecuación entre el monoteísmo y la monarquía universal.

Por todo ello, el Emperador no es solo el jefe del ejército, el juez supremo y el único legislador, sino que también es el protector de la Iglesia, el obispo "exterior" cuya vida está regida por una misión providencial, que consiste en someter a todos

\footnotetext{
${ }^{2}$ Obsérvese la pequeña diferencia con la frase que ha llegado hasta nosotros "In hoc signo vinces".
} 
los pueblos y hacer reinar el cristianismo sobre todo el orbe, y esta función propagadora de la fe entre los paganos es la que conforma uno de los principales títulos del nuevo emperador cristiano, el de "isapostolos" (semejante a los apóstoles). El carácter providencial y sagrado del poder imperial fue uno de los factores más importantes para el mantenimiento de una gran inestabilidad en el acceso al poder, ya que impedía la consolidación de una clara ley de sucesión al trono. Por un lado, el Imperio era una institución humana regida por la Providencia; por otro, el hombre no puede enmarcar a la Providencia en una ley, ya que ningún órgano constitucional puede representar la voluntad divina.

Esta voluntad divina solía manifestarse por el unánime consentimiento del pueblo, del ejército y del senado para entregar el poder a aquel que se creía designado por un decreto divino, lo cual ocurrió muy raras veces. En cualquier caso, el emperador reinante, por el simple hecho de la naturaleza providencial de su autoridad, poseía el derecho de asociar a un colega en el poder y el de designar su heredero. Por este tortuoso camino se introdujo en el Imperio el sistema hereditario, que, en sí mismo, resultaba incompatible con una sucesión imperial regida por la Providencia, y que en general no era aceptado por las grandes familias que no ocupaban el trono en ese momento y aspiraban a llegar a él. Todo esto colocaba al emperador a una altura infinita sobre los demás hombres, y por ello era venerado como un ser de naturaleza excepcional, elegido por la Providencia, cuya autoridad era de condición sobrenatural, y por tanto, tenía derecho a honores y reverencias inusitadas. Tales eran las bases del llamado culto imperial, de la liturgia de Palacio y de la nueva iconografía imperial.

La historia del Bajo Imperio, del Imperio Romano Oriental y de Bizancio nos revela una lucha secular entre estas dos doctrinas irreconciliables entre sí: por un lado, la importancia cada vez mayor que tenían los vínculos familiares, la tendencia a convertir el poder en hereditario, haciendo que todo un linaje participara del favor divino concedido a un antepasado; y, por otro, la del hombre providencial, salido la mayoría de las veces de niveles sociales inferiores, que, seguro de su valía, se apoderaba del poder por la fuerza y salvaba al Imperio. En este caso el golpe de estado se legitimaba porque "la victoria solo está en manos de Dios", es decir, si el rebelde ha vencido es porque la Providencia Divina lo ha elegido para gobernar el Imperio sustituyendo al anterior gobernante, que "por sus errores había perdido el favor de la divinidad".

En este contexto aparece la iconografía de la "Manus Dei" en la moneda, muy ligada a los golpes de estado. Este tipo de la "mano señalando desde el cielo" es la representación de la elección de Dios-Padre de un emperador, que recibe por tanto el apoyo de la Providencia, y que en teoría todo el mundo debe aceptar como tal, intentando evitar así posibles sublevaciones, que cuestionaran tanto sus decisiones como su legitimación para ocupar el poder, y lo vamos a encontrar legitimando usurpaciones y golpes de estado hasta el final de Bizancio ${ }^{3}$ : como ejemplo de este modelo podemos ver una moneda del emperador Juan Tzimisces (969-979) (Fig. 5).

\footnotetext{
${ }^{3}$ Más datos en José María de Francisco Olmos, "La Manus Dei en la Moneda Bizantina (siglos VIII-XII)", Crónica Numismática no 176 (diciembre de 2005), pp. 40-43.
} 

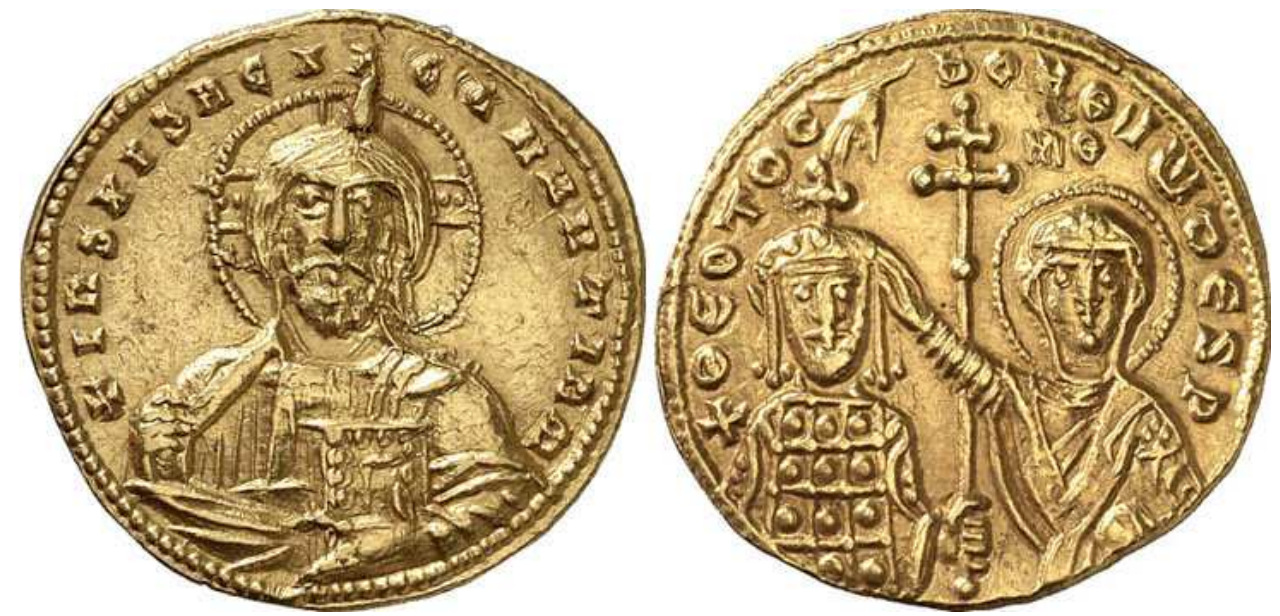

Fig. 5. DOC III/2, Juan I, n 3

Como vemos el uso de imágenes de la Divinidad se desarrolla en Bizancio por el problema político de la estructura del Imperio y de la sucesión, y a principios del siglo VIII aparecerá por primera vez en la moneda la imagen completa de Cristo (en época de Justiniano II), y luego, tras la crisis iconoclasta, también la de la Virgen, todo lo cual llegará a su culminación en época de los Macedonios, lo cual marcará la tipología monetaria bizantina hasta el final del Imperio. Pero, antes de esta revolución iconográfica, ya se había cristianizado un emblema tradicional pagano, la Victoria, muy presente en toda la numismática romana, por una figura que nos indica que la victoria está siempre en manos del Dios cristiano, y de nadie más, y por tanto debe representarse con una imagen cristiana, en este caso, un ángel (o un arcángel): así Justino I (518-527) introduce este tema cristiano en la moneda bizantina (Fig. $n^{\circ}$ 6), siendo el precedente de la iconografía del Arcángel San Miguel que ahora comentaremos.
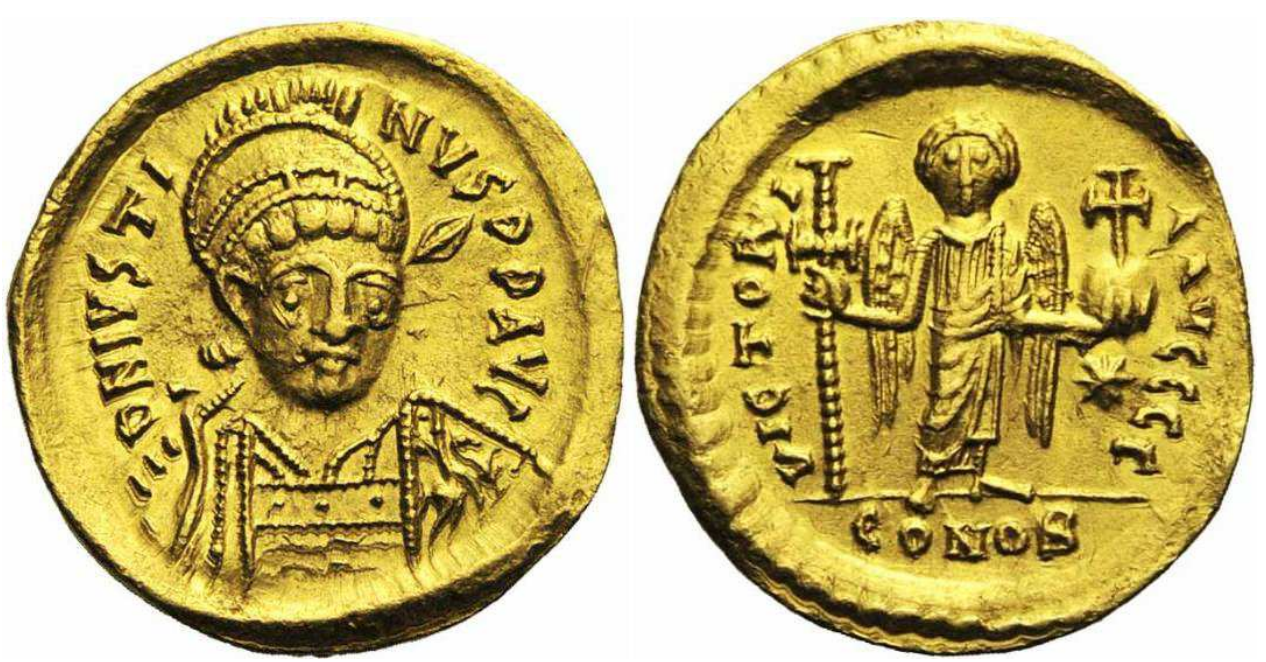

Fig. 6. DOC I, Justino I, n 2

Mientras esto ocurre en Oriente, en Occidente este desarrollo es mucho menor. Los visigodos van a copiar algunos temas bizantinos (cruz sobre gradas, tipo de Cristo...), y desde la época carolingia la Cruz va a ser el tema central de la moneda. Solo en siglos posteriores empezarán a aparecer otros temas propiamente cristianos, 
incluyendo no solo referencias a Cristo y la Virgen, sino que poco a poco aparecerán también frecuentes representaciones de santos, en especial en Italia y Alemania, como forma de legitimación política y religiosa de entidades no monárquicas, como, por ejemplo, el San Juan Bautista de Florencia o el San Ambrosio de Milán, o los santos patrones de diócesis y monasterios alemanes que tenían ceca propia, pero esto ya nos lleva a siglos posteriores.

\section{El arcángel San Miguel en la iconografía monetaria bizantina}

En el Cristianismo los arcángeles son una de las principales categorías de los ángeles. La Iglesia Católica acepta a tres específicos, Miguel (jefe de los ejércitos celestiales), Gabriel (el mensajero celestial) y Rafael (protector de los viajeros y de la salud), aunque asegura que existen siete. A Miguel se le suele representar en occidente con armadura, espada y también con la balanza del Juicio Final, mientras en Oriente también aparece con túnica y un globo crucífero, que representa el universo, sobre el que el Arcángel tiene todo el poder en nombre de Cristo; y de ambas maneras lo hemos visto representado en las monedas bizantinas comentadas. Un poco después, y dado que es el comandante en jefe de los ejércitos de Dios y el encargado de derrotar a Lucifer, se le representa también con una lanza (o espada) venciendo al dragón (o demonio). De hecho la Iglesia Católica le venera en todos sus papeles, como el principal enemigo de Satán y los ángeles caídos, a quienes vence; como el ángel de la muerte que conduce y protege a las almas, y también será quien las pese en su Balanza en el Día del Juicio Final, y, por último, como el Guardián de la Iglesia.

Su importancia política fue muy temprana, y ya el emperador Constantino le invocaba como su protector. De hecho existe la tradición de que se le apareció para confortarle y curarle, por lo cual el emperador mandó edificar en las afueras de Constantinopla una iglesia bajo su advocación, el Michaelion (en Sosthenion). Durante muchos siglos los fieles cristianos le asignaron como papel principal el cuidado de los enfermos y su sanación (en especial en su santuario de Frigia): de hecho su prestigio como sanador fue superior a su papel militar durante mucho tiempo. Sin embargo, los Padres Griegos reiteraban que es "Princeps militiae coelestis quem honorificant angelorum cives", y en su liturgia se le da el título de Archistrategos. A pesar de todo en Bizancio hay que esperar al siglo XII para que aumente su importancia militar, como veremos en las monedas.

En las monedas bizantinas no encontramos imágenes específicas de santos ni arcángeles hasta principios del siglo $\mathrm{X}$, cuando durante el corto reinado del emperador Alejandro (912-913) sus monedas ofrecen la imagen de un santo coronando al Emperador, que los especialistas identifican con su santo patrón, San Alejandro (obispo de Constantinopla en el siglo IV), (Fig. ${ }^{\circ}$ 7). Pero esta novedad no tendrá continuidad, y habrá que esperar a principios del siglo XI para encontrar a otro protector imperial específico, en este caso, ya sí, el arcángel San Miguel. 

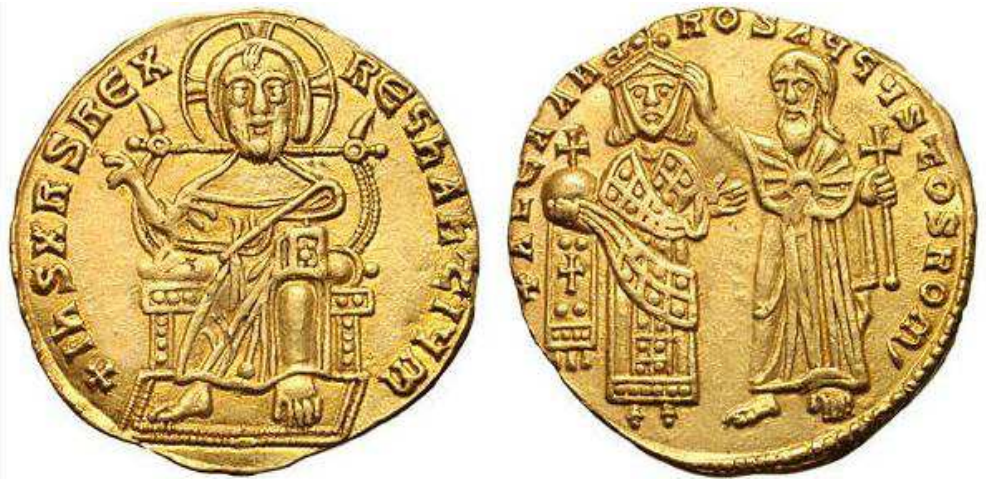

Fig. 7. DOC III/2, Alejandro, ${ }^{\circ} 1$

Al final de la dinastía macedónica no había más herederas que dos mujeres, Zoé y Teodora, y el poder imperial pasó a los varios maridos de la primera. Constantino VIII decidió, apenas tres días antes de morir, el matrimonio de su hija Zoé con el eparca de Constantinopla, Romano Argyros, que, a la muerte de Constantino (noviembre de 1028), subió al trono, sin oposición, como Romano III (1028-1034), con la única legitimidad que le daba su matrimonio. Zoé, una mujer muy activa, fue la instigadora de la muerte de Romano III (abril 1034), casándose el mismo día con su nuevo amante y emperador, el paflagonio Miguel IV (1034-1041). La familia del nuevo emperador se hizo rápidamente con el control de todos los resortes del poder, encerrando a Zoé en el gineceo, y para asegurar su poder, en 1041, obligaron a la emperatriz a adoptar como hijo y heredero a Miguel Calafate, sobrino de Miguel IV, en una grandiosa ceremonia celebrada en la iglesia de la Virgen de Blanquernas. Miguel IV murió el 10 de diciembre de 1041 y Miguel V subió al trono de forma automática. Su reinado duró apenas 132 días. Sus primeras medidas fueron bien acogidas, pero, cuando ordenó desterrar a la emperatriz Zoé (18 de abril de 1042), el pueblo de Constantinopla se levantó contra él. Como Zoé estaba prisionera en el Gran Palacio, la multitud sacó a su hermana Teodora del monasterio de Petrión y la llevó a Santa Sofía, donde fue coronada emperatriz. Al día siguiente Miguel V y su familia eran cegados y encerrados en diversos monasterios. La legitimidad había triunfado, el pueblo aceptaba a los maridos de la legítima heredera, pero eran ellas, las hijas de Constantino VIII, las que simbolizan la dinastía, la continuidad y la tradición, y no se podía aceptar que se atentara contra ellas.

En este problemático contexto político hay que entender el precioso ejemplar acuñado por Miguel $\mathrm{IV}^{4}$ (Fig. $\mathrm{n}^{\mathbf{0}}$ 8) en la ceca de Tesalónica, que muestra al emperador señalado por la Manus Dei (ya que su legitimidad era solo por matrimonio) y la figura del Arcángel San Miguel entregándole el estandarte imperial, considerado como el protector del emperador, en este caso más en el sentido de sanador que en el militar ${ }^{5}$.

\footnotetext{
${ }^{4}$ Problemas de atribución, algunos autores lo atribuyen a Miguel V; más datos en Alfred Bellinguer, Philip Grierson y Michael F. Hendy, Catalogue of the Byzantine Coins in the Dumbarton Oaks Collection and in the Whittemore Collection (DOC), Washington, 1993, Tomo III pp.720-723.

${ }^{5}$ La salud de Miguel IV era delicada y el arcángel era muy venerado en Bizancio en su vertiente de protector de la salud y curador.
} 


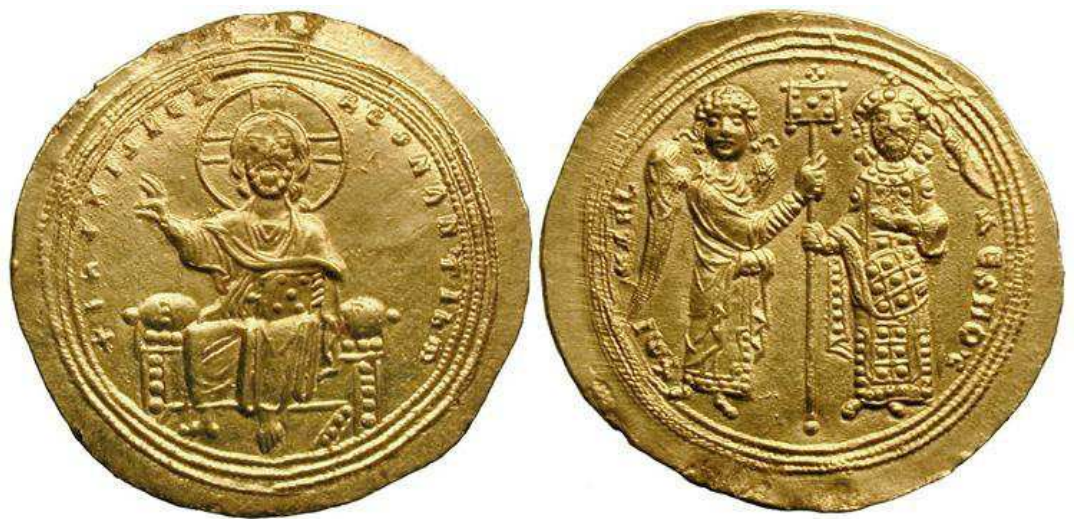

Fig. 8. DOC III/2, Miguel IV, $\mathrm{n}^{\mathbf{o}} 2$

Más de un siglo después el Arcángel reaparece en la moneda bizantina. Isaac II Angelus (1185-1195), que sucede a Andrónico Comneno en medio de una crisis política sin precedentes, consigue estabilizar la situación frente a búlgaros, normandos y occidentales, tanto en lo político como en lo económico, y, dado que era muy devoto del Arcángel, no solo restauró varias iglesias dedicadas al mismo (como la de Anaplus en el Bósforo), sino que decidió colocar su figura en sus monedas, algo que como hemos visto era excepcional. La imagen que se muestra es la tradicional, el emperador señalado por la Manus Dei y respaldado por el arcángel, que es su especial protector, y por primera vez sus vestiduras son totalmente militares y lleva una espada envainada, indicando el nuevo papel que se le da en Bizancio, ligado a la milicia. Así lo vemos especialmente en las piezas de oro (el hyperpyron) (Fig. 9), y también en el aspron electrum trachy (Fig. 10), donde es el Arcángel quien corona al emperador.
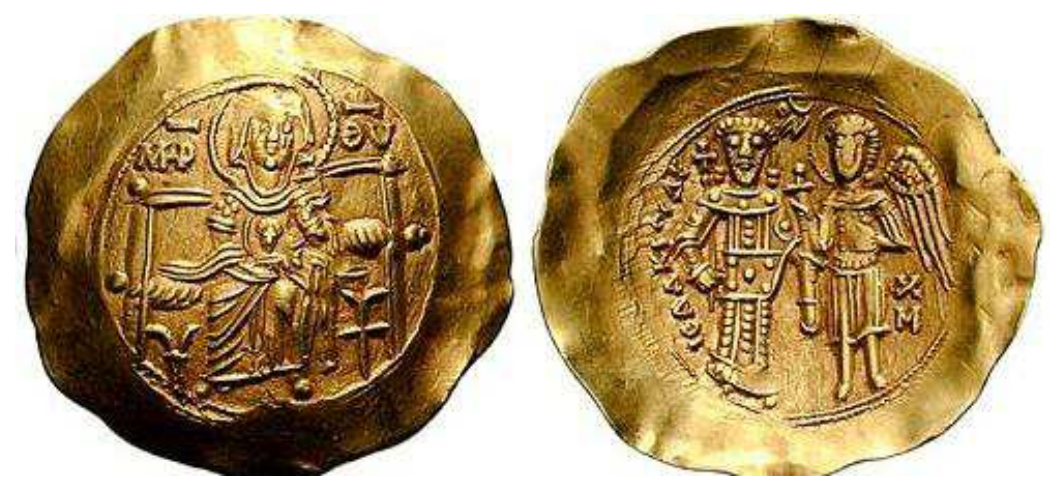

Fig. 9. DOC IV/1, Isaac II, ${ }^{\circ} 1$
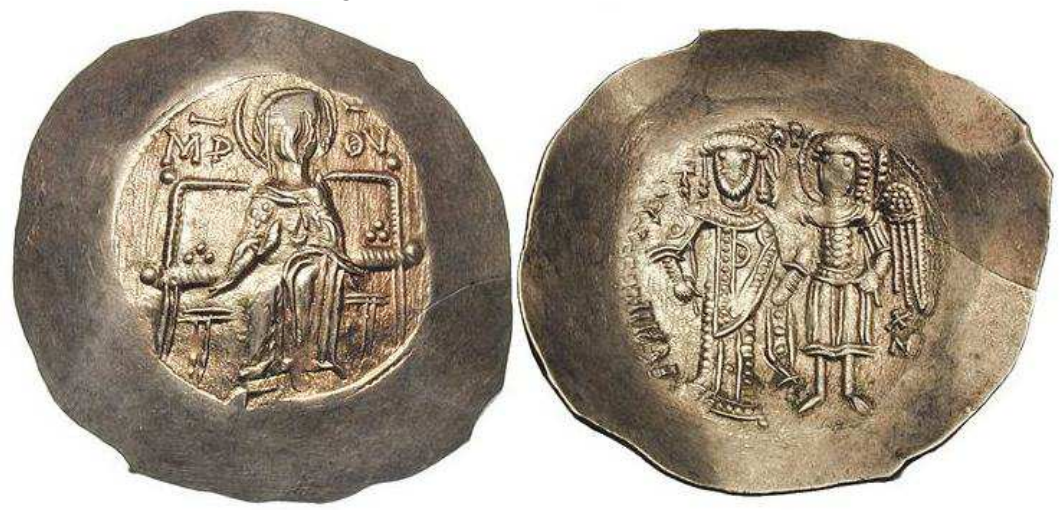

Fig. 10. DOC IV/1, Isaac II, $n^{\circ} 2 a$ 
Estas novedades van todavía más allá, y en algunas emisiones de la ceca de Tesalónica (tetarteron) el Arcángel aparece en solitario dominando totalmente la iconografía del anverso de la moneda, alcanzando una categoría que hasta ese momento solo habían tenido en la numismática bizantina Cristo y la Virgen (Fig. $11)$.
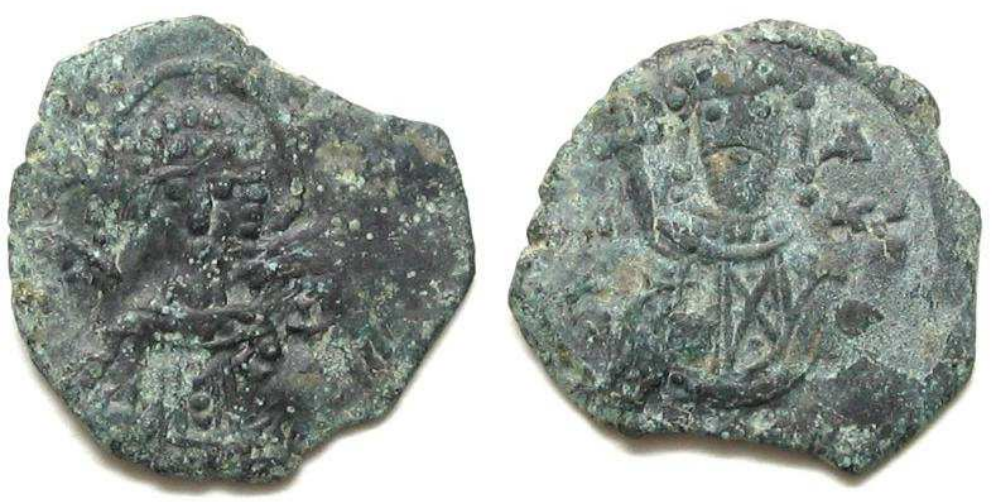

Fig. 11. DOC IV/1, Isaac II, $n^{\circ} 5$

Poco después los Latinos ocuparán Constantinopla (1204-1261) durante la mal llamada IV Cruzada y tomarán para sí la iconografía del Arcángel. Por ello encontramos algunos monedas donde Cristo está en anverso y el Arcángel San Miguel domina el reverso; a continuación vemos unos trachys (Fig. nº 12) donde aparece de frente, con ropas militares, sosteniendo cetro y globo crucífero.
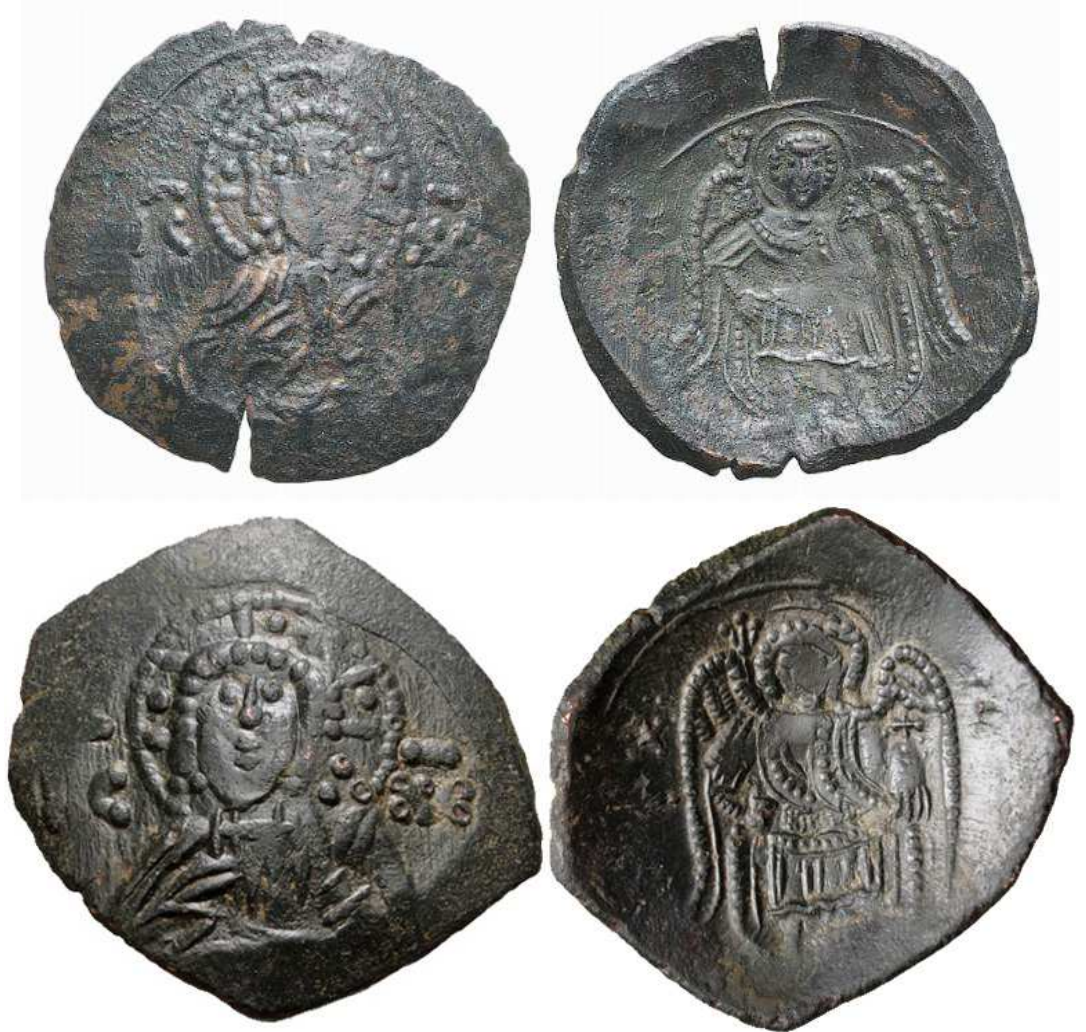

Fig. 12. DOC IV/2, Gobernantes Latinos, $\mathrm{n}^{\circ} 16$

Para terminar el repaso previo por la iconografía del Arcángel en la moneda bizantina hay que hablar de Miguel VIII Paleólogo (1259-1282). Su carrera política 
le llevó a ser el jefe del ejército del Imperio de Nicea, aprovechó la minoría de edad de Juan IV Láscaris para convertirse en coemperador y gobernante de facto, algo que ya había ocurrido frecuentemente en épocas anteriores, cuando el hombre "providencial" tomaba las riendas del estado, aunque manteniendo al emperador legítimo en el trono como garantía de legitimidad en el ejercicio del poder.

Miguel VIII era un gran político y consiguió culminar la reconquista bizantina aliándose con los genoveses (tratado de Ninfea, 13 de marzo de 1261) y tomando Constantinopla (25 de julio de 1261), donde hizo su entrada triunfal el 15 de agosto. Y como muestra pública de la restauración imperial fue coronado solemnemente en Santa Sofía junto a su esposa (septiembre), mientras su hijo Andrónico (tres años) era proclamado como coemperador. En medio de estos festejos se echó en falta la figura del legítimo emperador, Juan IV, que permanecía en Nicea.

Antes de finalizar el año Miguel VIII realizó su último movimiento para convertirse en único emperador: ordenó cegar al joven Juan IV y le encerró de por vida en la fortaleza de Dacityza. Se retrocedía así en la implantación del principio dinástico, pero el horror que produjo aquel crimen, incluso entre los servidores más cercanos de Miguel VIII, nos demuestra la fuerza que había adquirido el sentimiento de respeto a la legitimidad dinástica. Miguel pasó por la vergüenza de ser excomulgado por el patriarca Arsenio y de aguantar públicamente sus reproches. La deposición inmediata de Arsenio por orden imperial no calmó la indignación del pueblo. Miguel solo pudo justificarse alegando la voluntad divina, y en su autobiografía se justifica con esta frase: "¿Quién, pues, Señor, proclamará tu poderío? tu diestra es la que me ha elevado"6.

Como todo usurpador se creía un instrumento de la Providencia y justificaba su crimen por la razón de Estado. En sus monedas aparece de rodillas bajo la protección del Arcángel San Miguel, su santo patrono, que le lleva ante la divinidad, siendo entonces coronado por el mismo Cristo, mientras en el reverso aparece la Virgen, en este caso la de Blanchernas, protectora de Constantinopla, rodeada de las murallas de la ciudad reconquistada ${ }^{7}$. El mismo reverso aparece en piezas de plata trachy, lo cual nos da idea de la importancia simbólica del mismo (Fig. 13 y 13 bis).
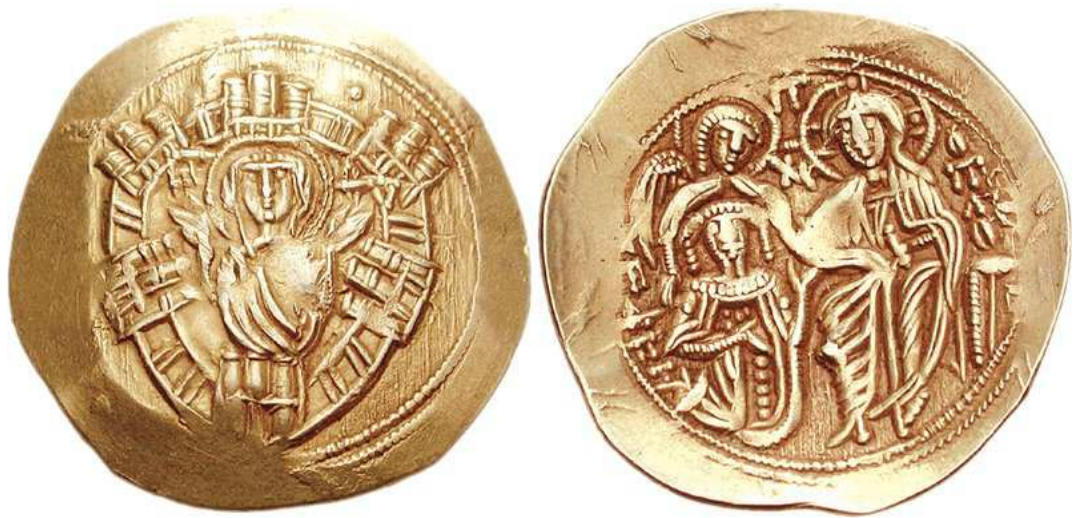

Fig. 13. DOC V/1, Miguel VIII, $\mathrm{n}^{\circ} 1$

${ }^{6}$ C. CHAPMAn, Michel Paléologue, restaurateur de l'Empire byzantin, París, 1926, pp. 166-168.

${ }^{7}$ Sobre este tema ver A. CUTLER, Transfigurations: Studies in the Dynamics of Byzantine Iconography, Pennsylvania-Londres, 1975. 

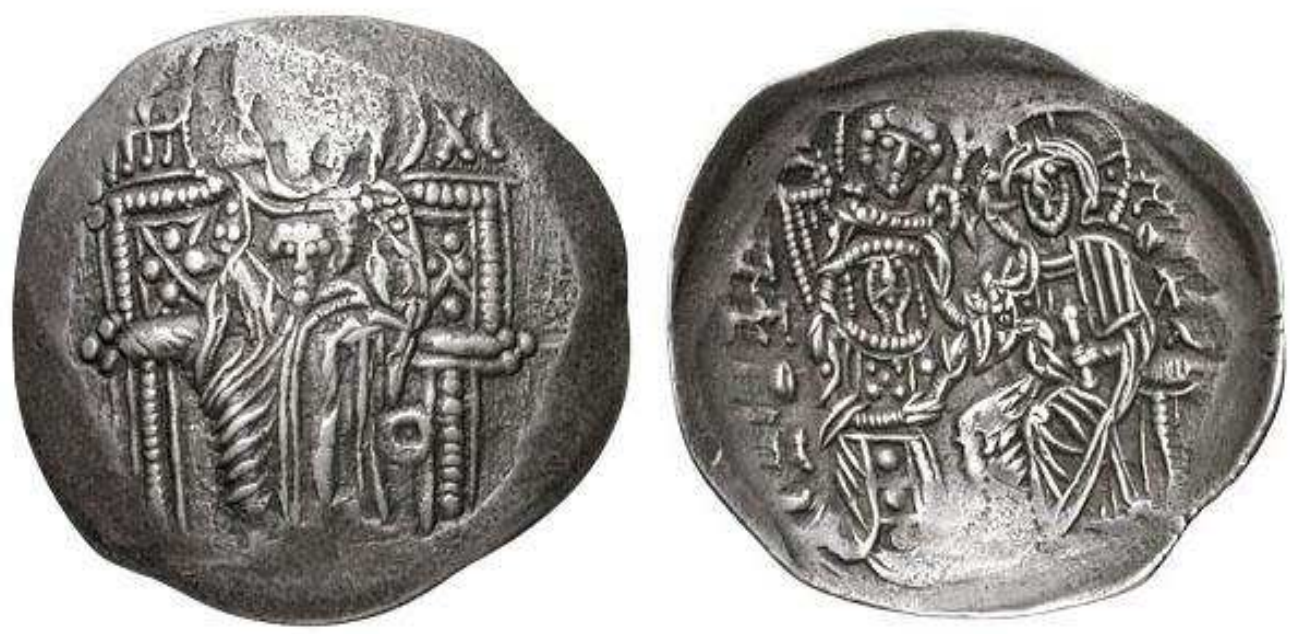

Fig. 13bis. DOC V/1, Miguel VIII, $\mathrm{n}^{\circ} 30$

En esta misma línea iconográfica encontramos al Arcángel abrazando al Emperador en unas piezas de plata de la ceca de Magnesia (Fig. 14). Hay que recordar aquí la especial devoción del emperador por el Arcángel: sabemos que hizo construir una gran estatua de bronce del mismo, colocándola en una alta columna delante de la iglesia de los Santos Apóstoles, el gran mausoleo imperial, mientras el emperador de rodillas le ofrecía la ciudad de Constantinopla para que fuera su protector $^{8}$.
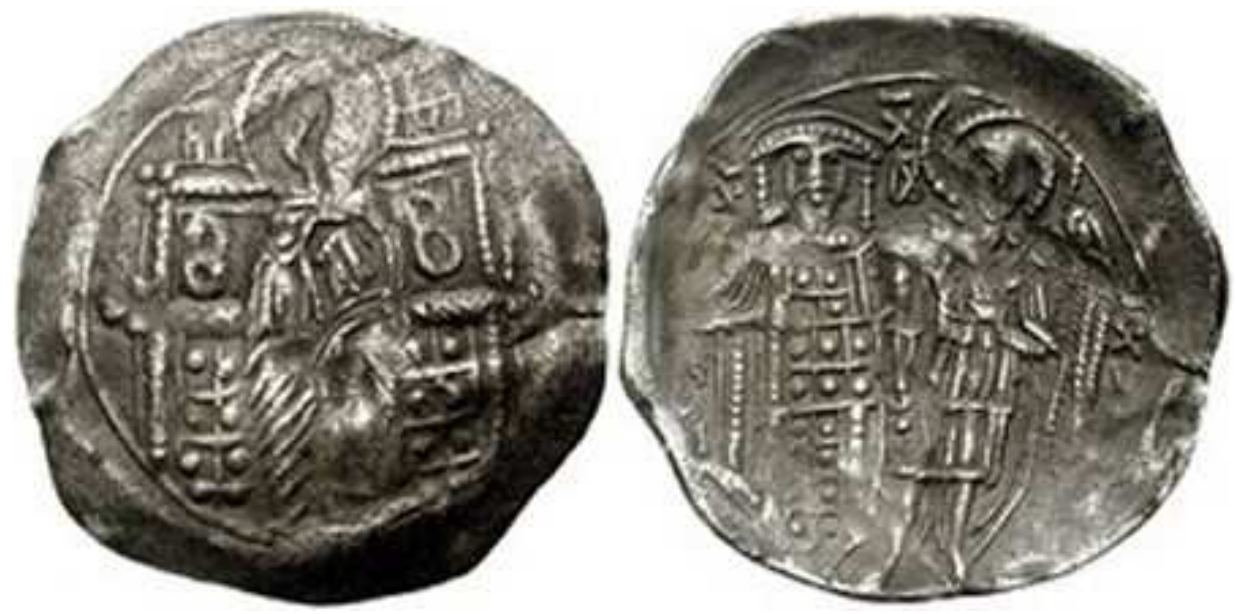

Fig. 14. DOC V/2, Miguel VIII, $n^{\circ} 27$

Además de esta aparición del Arcángel, hay otras acuñaciones donde todavía tiene un papel más relevante su figura. Así en un trachy de la ceca de Magnesia aparece dominando el anverso en solitario, con espada y escudo, mientras en reverso el emperador está acompañado de San Jorge, sosteniendo ambos conjuntamente el lábarum (Fig. 15).

\footnotetext{
${ }^{8}$ A.M.Maffry TALBOT, "The Restoration of Constantinople under Michael VIII", Dumbarton Oaks Papers, 47 (1993), pp. 243-261. 

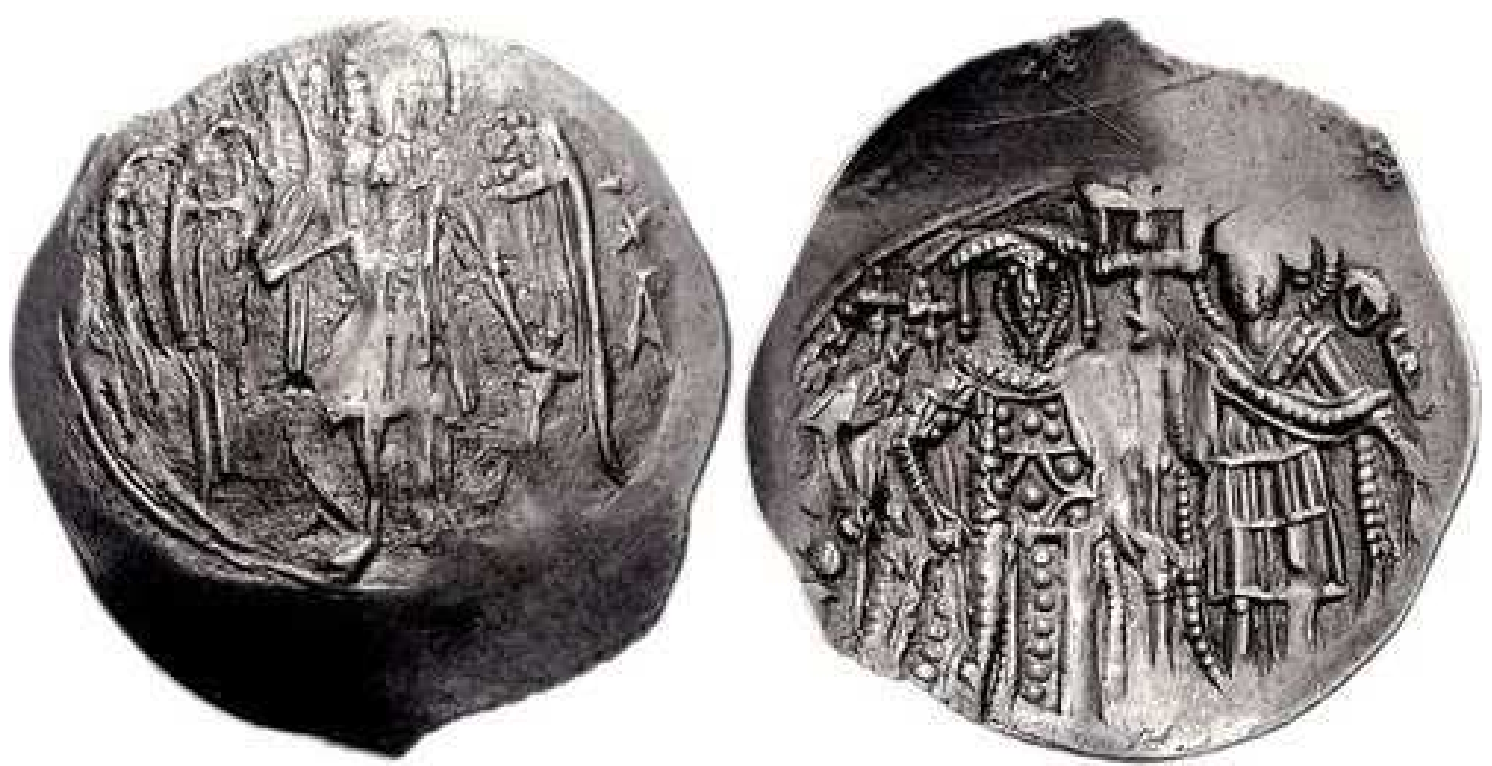

Fig. 15. DOC V/2, Miguel VIII, $n^{\circ} 26$

Del mismo modo encontramos otras acuñaciones donde de nuevo el Arcángel tiene un protagonismo muy especial: en la primera, de Magnesia, San Miguel domina de nuevo el anverso, apareciendo de frente armado con espada desnuda, mientras en el reverso Cristo corona al Emperador (Fig. 16); y en la segunda, de Thessalonica, es San Demetrio (santo defensor de la ciudad) el que aparece en anverso, mientras en reverso son Miguel VIII y su hijo y heredero (ya coronado coemperador) Andrónico II, los que aparecen de frente, siendo coronados por el Arcángel, del que se ve su cabeza nimbada y las alas extendidas que se colocan sobre ambos gobernantes (Fig. $n^{\text {o }} 17$ ).
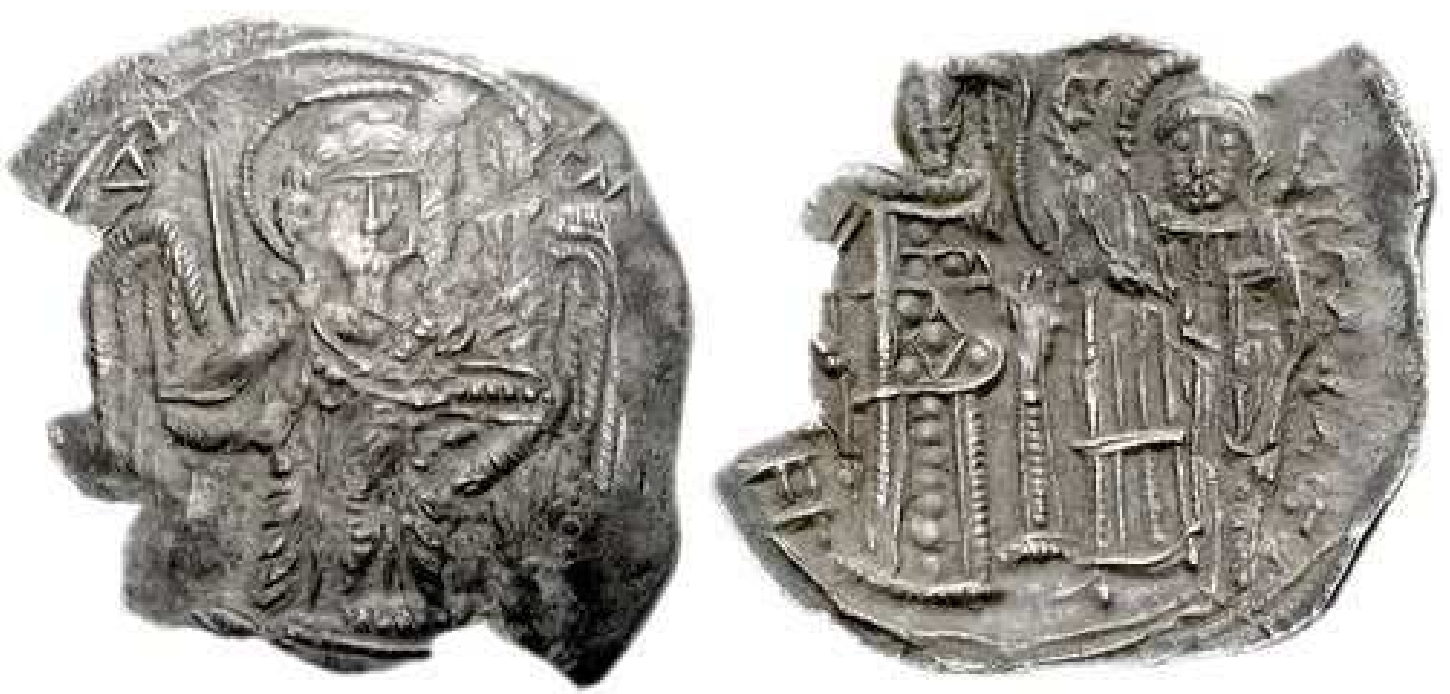

Fig. 16. DOC V/2, Miguel VIII, $\mathrm{n}^{\mathrm{o}} 34$ 

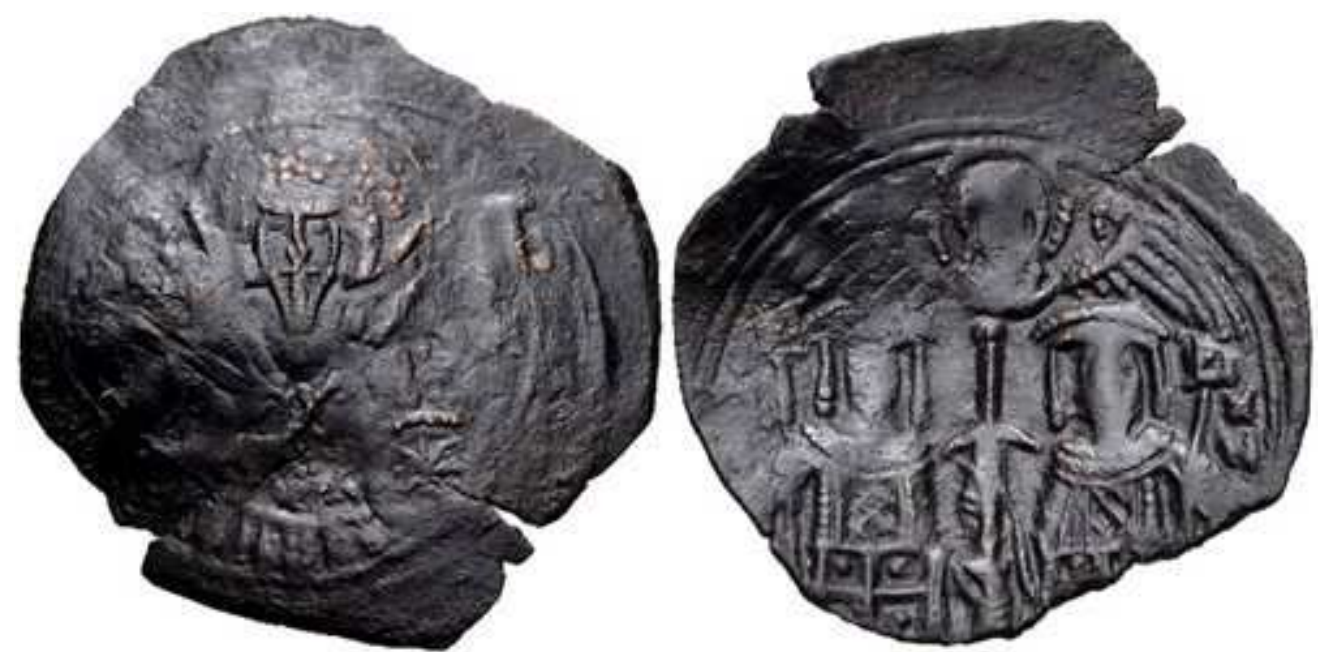

Fig. 17. DOC V/2, Miguel VIII, $n^{\circ} 36$

Por último, y como culminación de todo lo anterior, vemos una pieza donde nuestros dos protagonistas comparten la moneda de forma individualizada: el Arcángel San Miguel, con espada desnuda y globo crucífero, en anverso y el emperador Miguel VIII en reverso (Fig. nº 18)
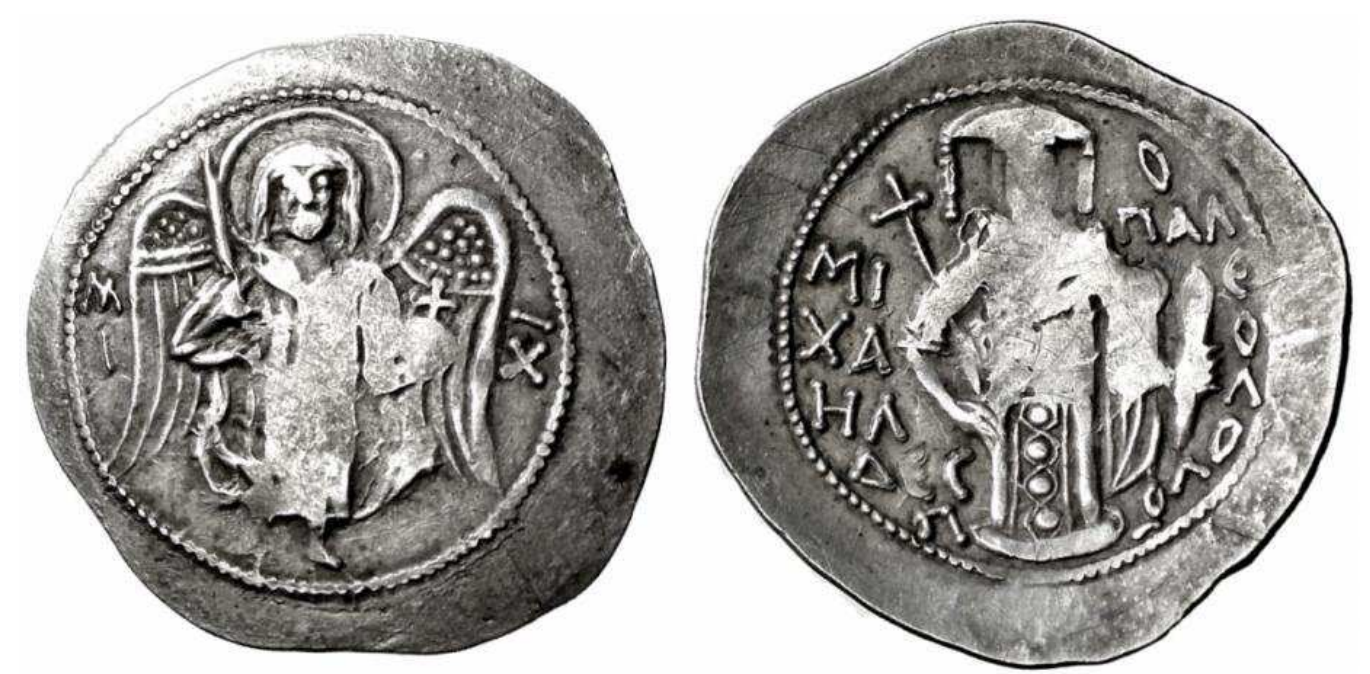

Fig. 18. DOC V/2, Miguel VIII, nº 114

Hemos visto cómo en Bizancio la figura del Arcángel San Miguel toma un protagonismo muy especial: primero en la primera mitad del siglo XI con Miguel IV el Paflagonio, en su vertiente sanadora; en el siglo XII ya aparece en su vertiente militar con Isaac II Angelo; y por fin en el XIII llega a su cima con Miguel VIII Paleólogo, donde se convierte de forma oficial en protector del Emperador y de la ciudad de Constantinopla, y, por ende, de todo el Imperio Bizantino.

\section{El arcángel San Miguel en Occidente}

Todo lo anterior nos muestra la importancia del Arcángel San Miguel en el desarrollo de la Iglesia, y en Occidente hay que añadir también la importancia de dos santuarios dedicados a su figura. En Italia tenemos el santuario del Monte Gargano 
(Foggia), muy antiguo en su devoción: nos dice la leyenda (compilada por Jacobo de la Vorágine en su Leyenda Aurea en la segunda mitad del siglo XIII) que el Arcángel se apareció al obispo de Sipontum (Manfredonia) a finales del siglo V para ofrecer su protección a la ciudad contra las invasiones de paganos y el papa Gelasio I ordenó la construcción de una basílica para conmemorar este hecho. Unos siglos después los habitantes de Sipontum achacaron a su intervención su victoria contra los bizantinos (663), y desde ese día (8 de mayo) la festejaron de forma especial bajo la advocación de la Aparición de San Miguel (lo cual confirmó siglos después San Pío V). Estos hechos hicieron del Monte Sant'Angelo un importante lugar de peregrinación, donde acudieron papas (Gelasio, León IX, Urbano II, Alejandro III, Gregorio X, Celestino V...), santos (Brígida de Suecia, Bernardo de Claraval, Tomás de Aquino, Francisco de Asís) y soberanos (Otón III, Matilde de Toscana, Carlos I de Anjou...), así como cientos de miles de personajes anónimos. En Francia se encuentra su otro gran santuario de Occidente, el conocido como Mont Saint-Michel, en la baja Normandía, donde se encuentra la abadía consagrada al culto del Arcángel (Mons Sancti Michaeli in periculo mari), que tiene su origen en época de los merovingios, cuando según la leyenda el obispo Aubert de Avranches construyó un oratorio (708) dedicado a San Miguel a petición del mismo arcángel, que se le apareció en varias ocasiones, y desde entonces se convirtió en uno de los lugares de peregrinaje más importantes del occidente medieval (junto a Roma y Santiago de Compostela), aunque pasó por épocas muy complicadas hasta su definitiva construcción a principios del siglo XIII gracias a la protección del rey Felipe II Augusto.

Estos lugares de peregrinación y su importancia en el culto de la Iglesia llevaron a San Miguel a convertirse en un referente, reforzando además su perfil militar en una época en que la caballería empezó a dominar la sociedad occidental. De este modo a finales de época medieval va a alcanzar gran importancia en la iconografía política monetaria de Francia, Inglaterra y Nápoles.

\section{El arcángel San Miguel en la iconografía monetaria de Occidente}

El primer tipo monetario con San Miguel lo encontramos en Francia en la primera mitad del siglo XIV, cuando Felipe VI de Valois (1328-1350) ordena acuñar una nueva moneda de oro denominada Ange d'or ${ }^{9}$, una de las más bellas del período, que muestra en anverso al Arcángel con túnica y lanza clavada en el dragón que está a sus pies, añadiendo a su tradicional iconografía una corona en la cabeza y que sostenía el escudo de Francia con su nuevo diseño, abandonando el tradicional sembrado de lises por únicamente tres flores de lis (Fig. 19).

\footnotetext{
${ }^{9}$ Tres emisiones, la primera por ordenanza de 27 de enero de 1341, la segunda de 8 de agosto de 1341, y la tercera de 26 de junio de 1342. Las piezas era de oro puro (24 quilates), la primera con un peso de 33 piezas en marco y un curso legal de 75 sueldos torneses, la segunda mantiene su valor pero rebaja su peso a 38 piezas por marco, y la tercera lo disminuye hasta las 42 piezas por marco, elevando su curso legal hasta los 85 sueldos torneses. Adrien BLANCHET \& Adolphe Edomnd DiEUdOnNE, Manuel de Numismatique Française, Paris, 1930, pp.247-249; y Louis CiANI, Les monnaies royales françaises de Hugues Capet à Louis XVI, Paris, 1926.
} 

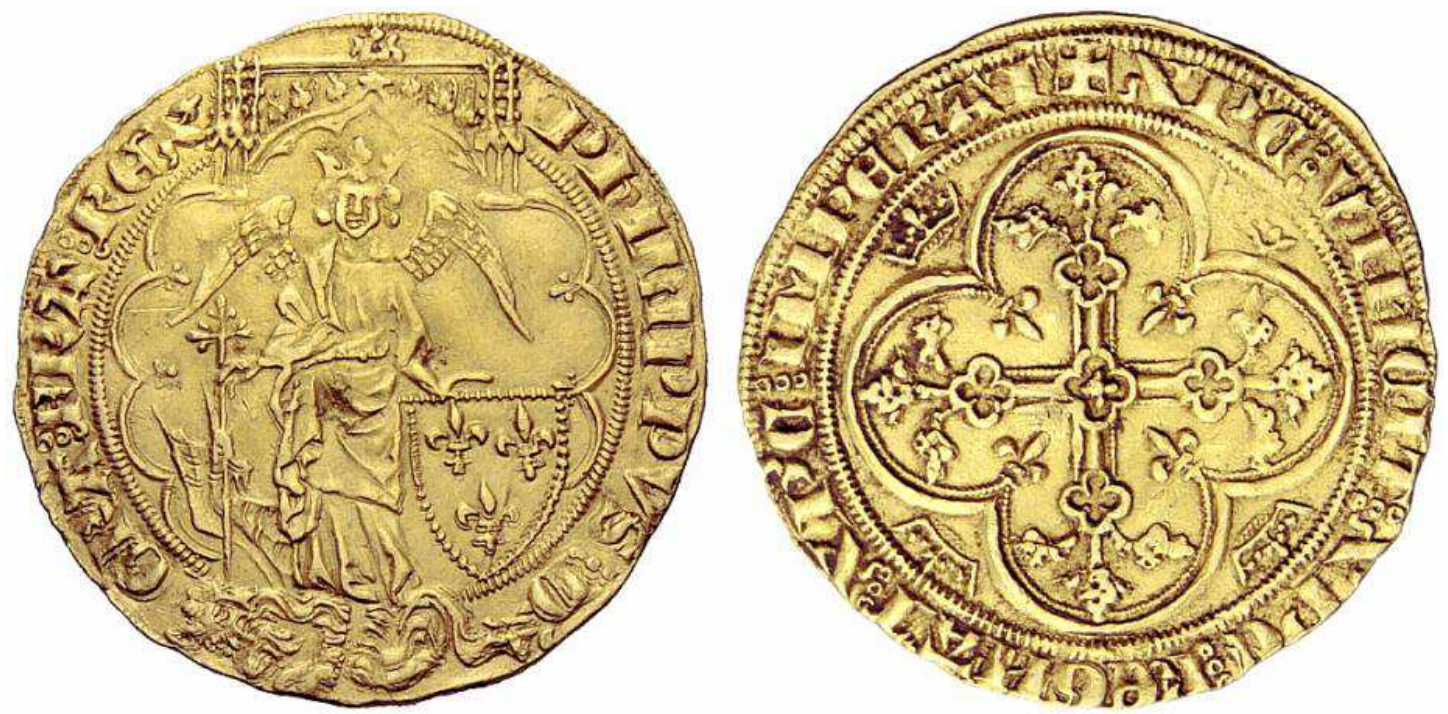

Fig. 19. Colección Particular (Ciani nº 277)

Felipe VI era el primero de su dinastía: en 1328 había muerto sin sucesión masculina el último de los Capetos, Carlos IV, y los nobles franceses apoyaron en la sucesión una estricta interpretación de la llamada ley sálica, que negaba a las mujeres el derecho no solo de sucesión sino también el de transmitir derechos, por lo cual el heredero del trono debería ser Felipe de Valois, descendiente por línea de varón de San Luis, y no Eduardo III de Inglaterra, hijo de Isabel, hermana de los últimos monarcas capetos. En un principio Eduardo III aceptó los hechos consumados e incluso prestó homenaje al nuevo rey por sus dominios de Guyena (1329), pero a poco a poco la situación se fue complicando, y en 1337 las hostilidades empezaron, Felipe VI confiscó Guyena al inglés, y Eduardo III empezó a cuestionar el derecho del Valois a sentarse en el trono francés escribiéndole una carta dirigida a Felipe de Valois, que se dice rey de Francia.

La lucha daría comienza en los Países Bajos, ligados económicamente a la lana inglesa. Los burgueses de Gante pidieron ayuda a Eduardo III y le prometieron reconocerle como a su legítimo rey; con ese apoyo Eduardo III decidió proclamarse rey de Francia y tomar sus armas como propias, entrando en Gante en enero de 1340, y en verano su flota derrotó a la francesa en L`Ecluse (antepuerto de Brujas). La Guerra de los Cien Años había comenzado.

Es en estos momentos cuando el rey Felipe VI va a acuñar su nueva moneda, introduciendo una tipología radicalmente distinta de todas las vistas con anterioridad y el motivo es estrictamente político. Igual que el Arcángel San Miguel fue el encargado de derrotar a los ángeles rebeldes a Dios, su legítimo señor, ahora Felipe VI, considerándose el legítimo rey de Francia por la Gracia de Dios, invoca al Arcángel para derrotar a unos súbditos desleales que se rebelan contra su legítimo señor, contraviniendo las leyes de Dios y de los hombres, en este caso Eduardo III de Inglaterra, vasallo del rey de Francia como señor de Guyena. Este fue sin duda el motivo de esta importante novedad tipológica, que desde entonces servirá para defender la posición de los reyes legítimos que luchan contra vasallos rebeldes. 
Más de cien años después reinaba en Francia Luis XI (1461-1483), que había sido un Príncipe rebelde a su padre, Carlos VII, por lo cual había pasado varios años viviendo en la fastuosa corte de su tío, Felipe, Duque de Borgoña. Una vez en el trono, buscó consolidar el poder de la Monarquía y reducir el de la alta nobleza, favoreciendo a la burguesía y a la pequeña nobleza, por lo cual tuvo que enfrentarse a varias revueltas nobiliarias, siendo la más importante la llamada Liga del Bien Público (marzo 1465), formada por Felipe III el Bueno, Duque de Borgoña; Francisco II, Duque de Bretaña; Juan II de Borbón y Juan V de Armagnac, entre otros, a los que luego se unió el propio hermano del rey, Carlos, Duque de Berry, que aprovecharon el descontento por el aumento de impuestos al pueblo y las medidas tomadas para controlar el patrimonio del clero y las universidades. Tras varios años de luchas y treguas, Luis XI firmó el Tratado de Ancenis (septiembre de 1468) logrando romper la Liga, haciendo la paz con Berry y Bretaña, y dejando aislado al nuevo Duque de Borgoña, Carlos el Temerario, con quien poco después volvió a enfrentarse.

En este contexto se producen en el verano de 1467 la muerte del Duque Felipe de Borgoña y la embajada inglesa de Richard Neville, Conde de Warwick, dos hechos que marcaron el nacimiento de la moneda que comentamos, el Angelot, que se hizo sin duda no tanto como una pieza regular más del sistema económico francés, sino más bien como una acuñación extraordinaria para servir de propaganda política a los complejos momentos por los que pasaba el reino, siendo la ordenanza que la regulaba de 19 de junio de 1467, y sabemos que algunas de las primeras piezas le fueron regaladas al Conde de Warwick durante su embajada.

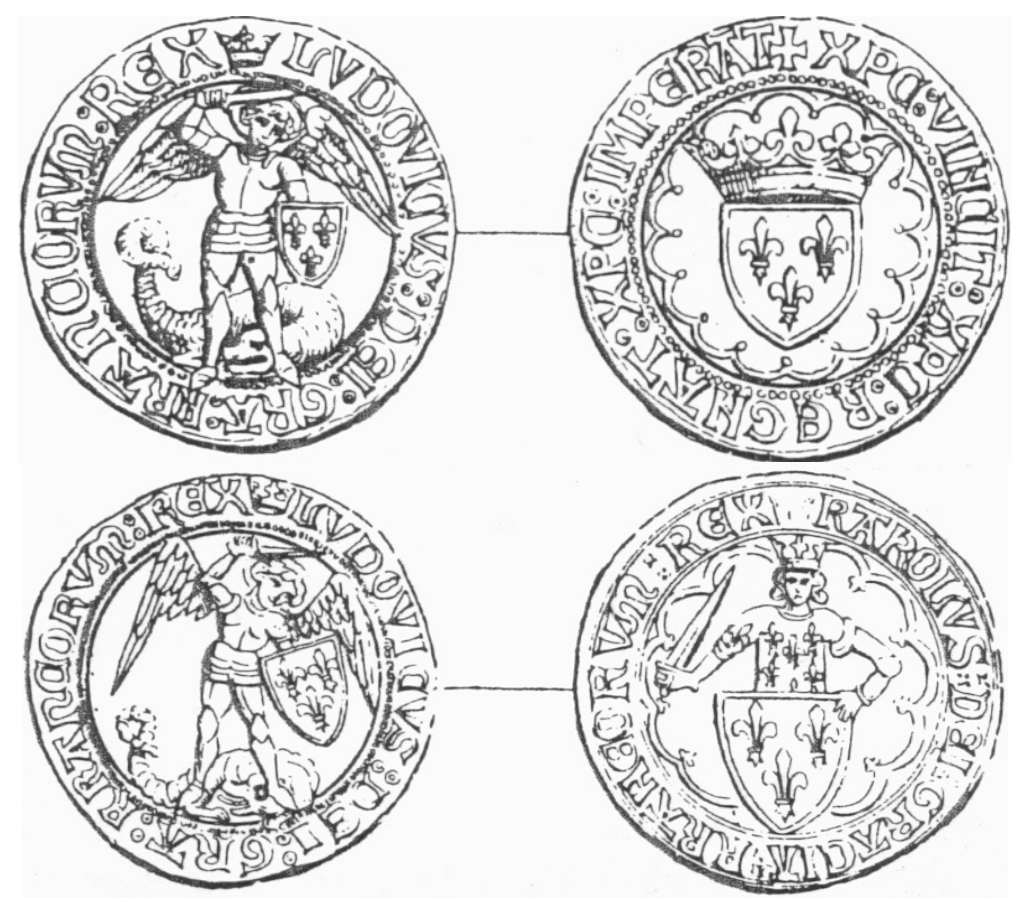

Fig. 20 y 20 bis (Ciani no 738 y 739)

Los modelos conocidos del Angelot que han llegado hasta nosotros muestran un mismo anverso: al Arcángel San Miguel con armadura completa y llevando el escudo real de Francia en su brazo, mientras con espada en alto se dispone a acabar 
con el dragón que está a sus pies, en tanto que los dos reversos que conocemos uno muestra las armas reales de Francia y otro al Rey de Francia con espada desenvainada y mostrando su escudo (Fig. 20 y 20 bis). Parece claro el mensaje en este verano de 1467: el Rey legítimo se defiende contra los vasallos rebeldes, por muy poderosos que estos fueran, teniendo el apoyo de su legitimidad divina, y, así como los rebeldes a Dios fueron derrotados por San Miguel, así las tropas reales acabarán con las rebeldes.

Es más, en este contexto de enfrentamiento con Borgoña, agravado desde 1468, el rey Luis XI va a crear la Orden de San Miguel (Amboise, 1 de agosto de 1469), como una especie de contrapunto de la orden del Toisón de oro borgoñona: su sede sería en principio la abadía de Mont Saint-Michel, aunque luego se trasladó a la Capilla de San Miguel del Palacio Real de París. Así el rey reforzaba la fidelidad de sus más estrechos colaboradores y de los grandes nobles, reivindicando de nuevo la lealtad de los vasallos como una de las principales virtudes a exigirles, en lo civil y en lo religioso, y también la utilizaba para fomentar sus alianzas diplomáticas. Los 36 caballeros que la formaban originalmente llevaban un collar de oro hecho de pequeñas conchas unidas por nudos, del que colgaba un medallón que representaba al Arcángel San Miguel matando al dragón.

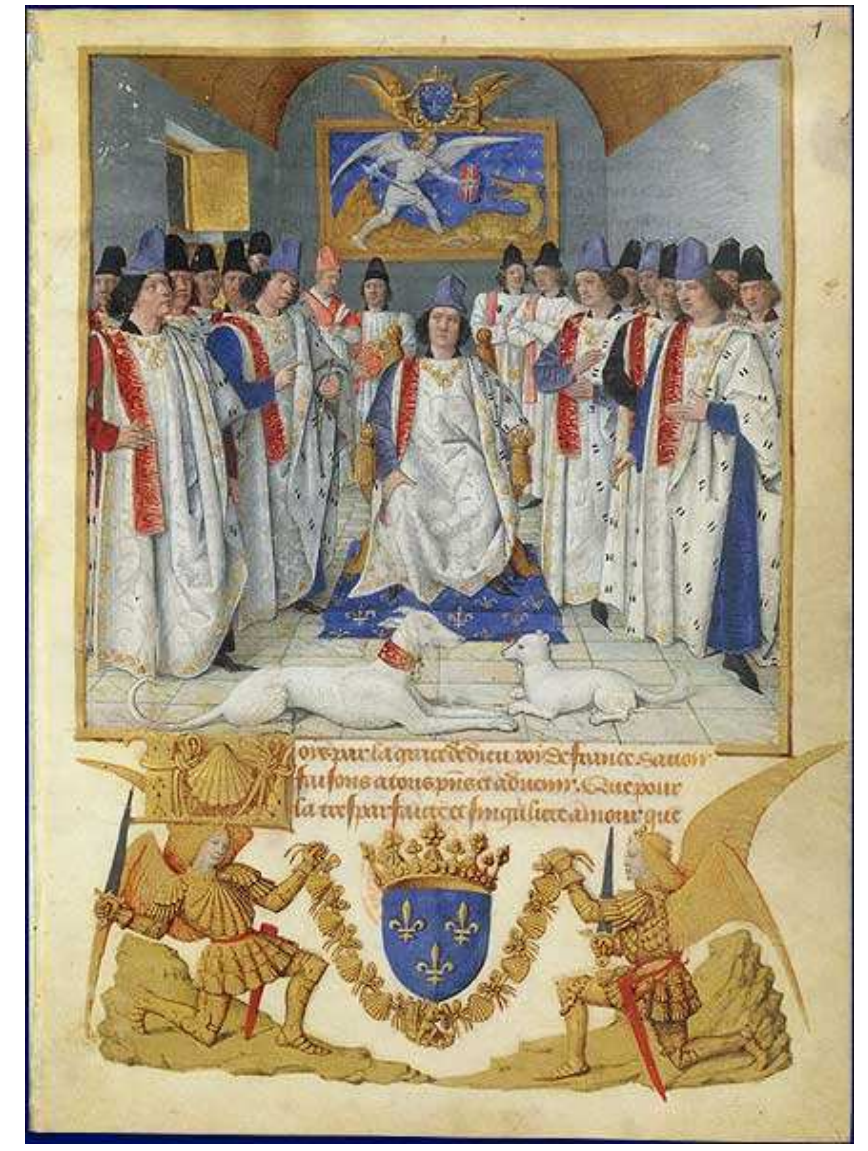

Fig. 21. Estatutos de la Orden de San Miguel (Paris, Bibliothèque Nationale, fr. 19819, fol.1)

A continuación vemos la preciosa miniatura que el iluminador Jean Fouquet hizo (1470) para el manuscrito de los Estatutos de la Orden (Paris, Bibliothèque Nationale, fr. 19819, fol.1) (Fig. 21), en el que se aprecia al rey Luis XI presidiendo 
el capítulo, donde se identifica a los grandes nobles, como a Carlos de Francia, hermano del Rey, el duque Juan de Borbón, Antoine de Chavannes...y al fondo se ve una tabla con San Miguel venciendo al dragón bajo el escudo real de Francia.

Mientras esto ocurría en Francia, al otro lado del Canal reinaba en Inglaterra Eduardo IV de York (1461-1483), que había depuesto a Enrique VI de Láncaster durante el largo conflicto de la Guerra de las Dos Rosas. Eduardo IV se declaró a sí mismo rey, y el 4 de marzo de 1461 fue proclamado en Westminster con tantas formalidades como fueron posibles, teniendo en cuenta que aún había otro rey vivo, Enrique VI, que fue declarado rey de alta traición. Como vemos una situación explosiva en una época en que el rey lo era por designio divino. Por fin Eduardo venció a los lancasterianos y se coronó el 28 de junio, mientras en noviembre de 1461 el Parlamento aprobó durísimas medidas contra los vencidos, que dirigidos por la reina Margarita atacaron de nuevo en 1462 y 1463 al nuevo monarca, y Somerset se levantó en 1464. Todos fueron derrotados por Eduardo IV, que ordenó ejecutar a todos sus enemigos, y como colofón final Enrique VI fue apresado y conducido a Londres, donde fue encerrado en la Torre. Pero la calma duró poco; ahora los yorkistas, dirigidos por Warwick y su hermano Northumberland, estaban descontentos con el rey y su política de favorecer a los parientes de su mujer, Isabel de Woodville. Así en el otoño de 1470 los Neville consiguieron sacar a Enrique VI de la Torre y gobernar en su nombre, pero Eduardo IV contratacó y unos meses después venció en Barnet, y Enrique VI fue ajusticiado (21 de mayo de 1471). Ahora Eduardo IV era dueño de su destino y soberano absoluto. Con estos datos se entiende bien que el rey quisiera reforzar su posición, no solo con los hechos sino también con la ley, divina y humana.

La tradicional moneda de oro inglesa de esos años era el Noble, en el que el monarca aparece sobre un navío mostrando el poder naval inglés (Fig. 22). Cuando Eduardo IV acabó con las últimas resistencias lancasterianas, decidió modificar esta pieza creando el llamado Angel o Angel-Noble, donde el anverso va a mostrar la tradicional imagen del Arcángel San Miguel alanceando al dragón, mientras en reverso se mantiene el navío de la anterior pieza, aunque ahora sin la imagen del rey, solo con el escudo de las armas reales sobre los que se coloca una gran cruz, ligada a la leyenda perimetral (PER CRUCEM TUAM SALVA NOS CHRISTE REDEMPTOR), colocando a los lados de la misma la inicial real (E) y la rosa blanca de los York (Fig. 23).
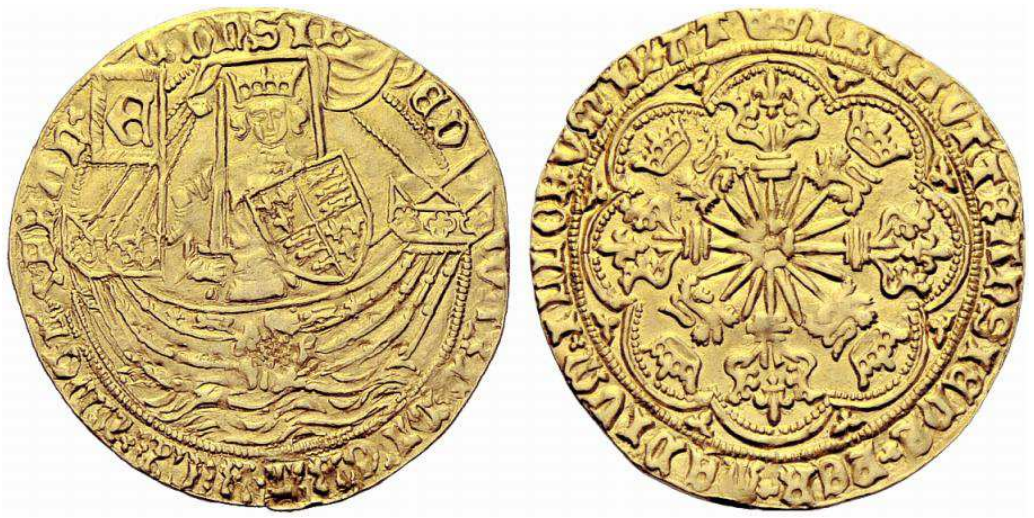

Fig. 22. Seaby 1946 

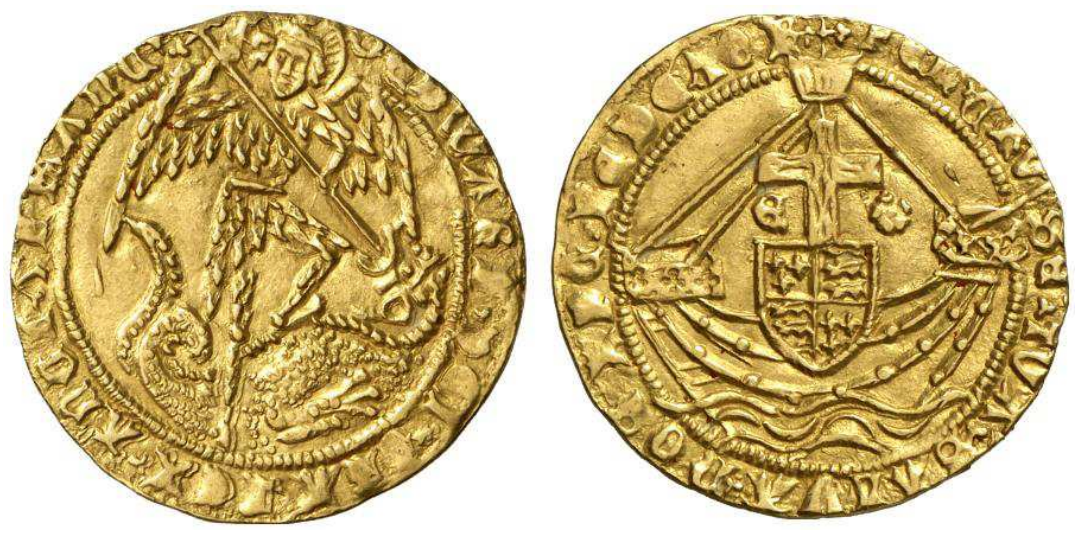

Fig. 23. Seaby 2092

El mensaje es claro: el nuevo monarca ha recibido de Dios la victoria, porque sus derechos le convertían en el legítimo rey de Inglaterra, elegido por la Providencia. Todos los que luchen contra él serán como Satanás, que se rebeló contra su Señor, y serán derrotados como lo hizo el Arcángel San Miguel. La inestabilidad política de Inglaterra hizo que este tipo monetario se mantuviera hasta el siglo XVII, en concreto, hasta el reinado de Carlos I Estuardo.

El gobierno de la Casa de Trastámara en Nápoles fue desde su inicio muy complicado: en primer lugar, el reino era feudo directo de la Santa Sede, por lo cual el rey necesitaba ser reconocido formalmente por el papa para poder gobernar legítimamente; en segundo lugar, tras doscientos años gobernado por los franceses de la Casa de Anjou, su sustitución por sus tradicionales enemigos aragoneses provocó en gran parte de la nobleza el rechazo absoluto de la nueva dinastía, además de las reclamaciones de los herederos de dicha Casa, apoyados siempre por el rey de Francia. Todos estos peligros llevaron al rey Ferdinando I de Nápoles (1458-1494) a acuñar ciertas piezas que intentaban legitimar su situación, tanto frente a sus súbditos, como frente a las potencias extranjeras que cuestionaban su legitimidad, colocando tipos y leyendas absolutamente excepcionales en la tipología medieval napolitana e incluso europea, pero que nos documentan claramente los problemas por los que pasó este monarca y que ahora analizaremos más detalladamente.

Las principales monedas que estudiaremos serán los "Coronatos", una moneda de plata que fue acuñada por los dos primeros reyes napolitanos de la Casa de Aragón: Ferrante I (1458-1494) y Alfonso II (1494-1495). Estas monedas son verdaderos documentos y deben ser analizadas paso a paso para entender su significado, explicar las razones por las cuales un rey de Nápoles se intitula rey de Sicilia, Jerusalén y Hungría, el significado de frases religiosas y aforismos utilizados, de los tipos representados, sean una cruz, el busto coronado del monarca, la escena de la coronación o un San Miguel matando al dragón: todo tiene un significado preciso, que hace referencia a un hecho concreto importante en el momento de la acuñación y que es necesario desentrañar documentalmente

Tras una larga lucha con el pretendiente francés, Renato de Anjou, Alfonso V de Aragón consiguió ocupar la práctica totalidad del territorio napolitano durante el verano de 1442 y Renato tuvo que huir a Francia, haciendo Alfonso su entrada triunfal en Nápoles el 26 de febrero de 1443 y consiguiendo la investidura oficial 
del reino por parte del papa Eugenio IV poco después ${ }^{10}$, en concreto en el 15 julio de $1443^{11}$, con lo cual ahora era ya rey oficialmente de las "Dos Sicilias", o como aparece en la documentación "citra et ultra Farum"12.

El rey Alfonso V de Aragón fue siempre un enamorado de Italia y delegó el gobierno de la mayoría de sus otros estados a personas de su confianza, tanto que Nápoles se convertiría pronto en su residencia definitiva, y el asegurar el futuro de este territorio se convertiría en su principal meta en la política internacional que iba a seguir desde entonces, ya que tenía la intención de dejárselo en herencia a su hijo bastardo, Ferdinando ${ }^{13}$, siguiendo la tradición hispánica de que los reinos conquistados podían ser traspasados sin estar sujetos a la ley de primogenitura, teniendo por obligación que pasar sus otros territorios a su hermano Juan II (Aragón, Valencia, Cataluña, Mallorca, Sicilia y Cerdeña).

Alfonso tenía una amante, Gueraldona Carlino, que el 2 de junio de 1424 le dio un hijo, a quien puso de nombre Ferdinando (luego generalmente conocido como Ferrante). Ferdinando se educó en Valencia y marchó a Italia en el verano de 1438, siendo nombrado caballero por su padre, que le dotó de una casa acorde a su rango, y fue nombrado en 1439 lugarteniente general del reino (abril). Este rápido ascenso no era sino una muestra de que Alfonso pensaba convertirle en su heredero en Nápoles Durante la fase final de la guerra contra Renato, Ferdinando estuvo siempre al lado de Alfonso, al igual que durante su entrada triunfal en Nápoles, por lo que, tras lograr la paz, el rey empezó a negociar con las fuerzas vivas del reino su reconocimiento como sucesor: de hecho, siempre que tuvo que ausentarse de Nápoles dejaría al frente del gobierno a Ferdinando. La carrera de este hacia la sucesión fue complicada: el primer problema era su nacimiento ilegítimo. Para salvarlo el rey usó dos vías: primero, como monarca emitió un privilegio de legitimación (17 de febrero de 1440), y luego solicitó también al papa una bula en

${ }^{10}$ Por el Tratado de Terracina de 14 de junio de 1443 se llegó a un acuerdo entre las partes. Eugenio IV tuvo que aceptar investir a Alfonso como rey de Nápoles, porque su situación era débil, ya que en esos momentos estaba enfrentado al Concilio de Basilea y había un antipapa, Félix VIII (Amadeo, duque de Saboya), elegido en 1438, y Alfonso había sugerido que podía conquistar Roma para entregarla a Félix y el Concilio, si Eugenio no accedía a sus demandas.

11 Sin embargo, luego hubo bastantes negociaciones para limar los detalles, tanto que las precisiones y las cesiones papales ante Alfonso se hicieron mediante doce bulas. La protocolaria ceremonia de investidura, por la cual Alfonso realizó el juramento de vasallaje reconociendo la soberanía papal, se realizó en mayo de 1445, y se dejó para más tarde la solemne coronación, que al final no tuvo lugar.

${ }^{12}$ En un documento fechado el 5 de diciembre de 1449 el rey Alfonso se intitula de la siguiente manera: "Alfonsus, Dei gracia rex Aragonum, Sicilie citra et ultra Farum, Valencie, Hierusalem, Hungarie, Maioricarum, Sardinie et Corsice, comes Barchinone, dux Athenarum et Neopatrie, ac eciam comes Rossilionis et Ceritanie...". Agustín Millares CARlo, Tratado de Paleografía Española, tomo III, documento 336, Madrid, 1983.

${ }^{13}$ En el Tratado de Terracina una de las condiciones de Alfonso fue que el papa legitimara su propia adopción por la reina Juana II de Anjou, y el nacimiento de su hijo Ferdinando, y Eugenio IV tuvo que aceptar. Por Bula de 13 de diciembre de 1443 confirmaba la adopción de Alfonso por Juana, y por otra Bula de 14 de junio de 1444 legitimaba a Ferdinando, con lo cual la cláusula de la investidura que precisaba que, si don Alfonso moría sin hijos legítimos, el reino volvía a poder de la Iglesia, quedaba salvada. 
el mismo sentido, consiguiéndola de Eugenio IV (14 de junio de 1444); entretanto hizo que los barones le "pidieran" que la sucesión recayera en Ferdinando (Benevento, 1441), y que reiteraran sus intenciones en un parlamento pleno (monasterio de San Lorenzo de Nápoles, 1443). El rey aceptó, nombrando a Ferdinando duque de Calabria, título que se solía otorgar a los herederos del reino. Poco después los barones le prestaron homenaje como tal. Para confirmar la nueva situación política, el rey casó al duque de Calabria con Isabel Chiaramonte (1445), sobrina del principal barón del reino, el príncipe de Tarento, Giovanni Antonio del Balzo Orsini, intentando así asegurarse el apoyo de la levantisca nobleza.

Pero la sucesión de Ferdinando estaba lejos de ser fácil: por una parte, estaban los barones angevinos derrotados, que esperaban recuperar su poder, teniendo como pretendiente alternativo a Juan de Anjou (hijo del Renato derrotado por Alfonso V); mientras que los nuevos potentados catalanoaragoneses, que habían recibido beneficios en Nápoles, querían asegurar su posición no rompiendo los vínculos con la Corona de Aragón, por lo cual defendían que el reino pasase a Carlos de Viana, sobrino de Alfonso $\mathrm{V}$ y primogénito de su hermano Juan, o bien directamente a este último junto con el resto de la Corona de Aragón; por último, estaba el papa, que, como soberano feudal, nunca había aceptado de buen grado la conquista de Alfonso y solo esperaba un momento favorable para retirar la investidura del reino a su familia.

Frente a esta inestable situación, Ferdinando solo podía apoyarse firmemente en el ejército y la burguesía napolitana, a la que poco a poco, gracias a su firmeza, unirá otros aliados, que, si no eran completamente sinceros, al menos le apoyaron para impedir la victoria de un rival más peligroso.

Nada más morir su padre (27 de junio de 1458), Ferdinando tomó el poder ${ }^{14}$, pero el papa Calixto III (el valenciano Alfonso de Borja) decretó que el feudo napolitano volvía a su soberanía tras la muerte de Alfonso ${ }^{15}$, negándole a su hijo la investidura, con lo cual todos los enemigos de Ferdinando empezaron a preparar su rebelión al contar con una justificación legal, como era el apoyo del soberano feudal del reino, el papa, pero Ferdinando reaccionó convocando un parlamento general en Capua, que lo recibió por rey y legítimo sucesor, a pesar de las órdenes papales. Afortunadamente para Ferdinando, el papa cayó gravemente enfermo en julio y murió el 6 de agosto de 1458, siendo elegido como nuevo pontífice Eneas Silvio Piccolomini, que reinó como Pío II (1458-1464), y era mucho más favorable a llegar a un acuerdo político, tanto que poco después le concedió la tan deseada

${ }^{14}$ El testamento de Alfonso (fechado el día antes de su muerte) dejaba Nápoles a su hijo Ferdinando y sus descendientes, mientras que el resto de sus territorios, es decir, la Corona de Aragón, pasaba a su hermano Juan II (ya rey de Navarra), conforme a lo establecido en su testamento por el padre de ambos, Fernando I. Inmediatamente el duque de Calabria escribió al papa ( 1 de julio) para pedirle oficialmente la investidura. Ver Jerónimo ZURITA, Anales de la Corona de Aragón. Zaragoza, 1592 (Ed. de Angel Canellas, Zaragoza, 1967), libro XVI, capítulo XLVIII.

${ }^{15}$ Por bula de 12 de julio de 1458 el papa proclamaba el reino como perteneciente al papado en calidad de feudo caducado, y se aprestó a preparar una fuerza militar para conquistarlo, que iba a dirigir su sobrino, Pedro Luis de Borja, duque de Spoleto. 
investidura ${ }^{16}$ y mandó a un legado especial, el cardenal Latino Orsini, que le coronó en Bari el 4 de febrero de 1459.

Pero ese mismo año los enemigos de Ferdinando se levantaron en armas: Juan de Anjou invadió el reino en octubre y se le unieron importantes barones, como el Príncipe de Tarento y el duque de Rossano, y derrotaron varias veces a Ferdinando (batalla del Sarno, 1460), que tuvo que reagruparse para poder rechazar al invasor, al que solo pudo vencer en Troia el 18 de agosto de 1462, y, aunque Juan de Anjou no abandonó el reino hasta abril de 1464, su rebelión había sido derrotada, y la alianza de Nápoles con Florencia y Milán se fortaleció.

En este período Ferdinando hará sus primeras acuñaciones ${ }^{17}$, que muestran ya algunas características muy importantes y modernas para la época. Del período de la coronación hay que destacar dos piezas extraordinarias: en primer lugar, el ducado de oro, una de las primeras piezas con retrato renacentista, sin ninguna duda tomando como modelo el oro que a principios de los años 50 acuñó su consuegro y aliado Francesco Sforza, Duque de Milán, con la salvedad de que este busto lleva la corona real, como reverso aparece su escudo de armas, que cuartela su herencia napolitana (Hungría-Anjou-Jerusalén) con la aragonesa (Barras), y en las leyendas aparece con su nombre con su título real de Sicilia, Hungría y Jerusalén, y una frase evangélica: RECORDATUS MISERICORDIAE SUAE (San Lucas 1,54) (“Acogió a Israel, su siervo, acordándose de su misericordia", tomado del Magnificat).

Junto a este ducado acuñó en plata un Doble carlino (de algo más de 7 gramos de peso) con los mismos tipos y leyendas, cuya importancia radica en que es la primera moneda italiana en plata que lleva el nuevo retrato renacentista, y además es un múltiplo. En toda Europa se advierte la necesidad de tener una moneda de plata de más peso, y será en Italia donde se multipliquen los ensayos, y en todos los estados se acuñarán en la segunda mitad del siglo XV estas nuevas piezas y, como se pondrán en ellas retratos, se llamarán "testones" (los Sforza en Milán, los Este en Ferrara, los Gonzaga en Mantua, el Dogo Tron en Venecia, Sixto IV en Roma...).

Esta primera acuñación es por tanto puramente política, por un lado el rey coloca su retrato en ella como muestra de que es el propietario de la moneda y del reino, sin ninguna referencia a su soberano feudal, por lo cual sublima el concepto de legitimación dinástica: se considera el heredero de todos los reyes anteriores, y de sus reivindicaciones, por lo cual en su titulación aparecen los títulos tradicionales de rey de Sicilia y Jerusalén, pero también el de Hungría (reino que reclamaban los reyes Anjou napolitanos desde 1386), y como motivo central coloca su escudo de armas, donde cuartela la representación de su herencia biológica (Barras de Aragón) con la herencia política napolitana (Hungría-Anjou-Jerusalén) ${ }^{18}$.

\footnotetext{
${ }^{16}$ Pío II fue solemnemente coronado papa el 3 de septiembre, y el día 10 de noviembre otorgó oficialmente la investidura del reino a Ferdinando, fundándose en lo aceptado por sus predecesores Eugenio IV y Nicolás V, así como en los juramentos del reino al duque de Calabria como sucesor y en el testamento del rey Alfonso, revocando todos los actos que Calixto III había realizado contra Ferdinando.

${ }^{17}$ Para la historia de este reinado ver Ernesto PONTIERI, Per la Storia del Regno di Ferrante I d'Aragona re di Napoli, Nápoles, 1968.

${ }^{18}$ Para estas monedas ver Aloiss HEISS, Descripción general de las monedas hispanocristianas
} 
Tras la victoria sobre Juan de Anjou y los Barones, el trono de Ferdinando estaba ya seguro, y este ordenará hacer su segunda serie de acuñaciones, entre las que destacará especialmente la de una nueva moneda de plata, que se llamará "coronato" (1462). Esta pieza de plata iba a sustituir al antiguo "carlino", aumentando su peso ${ }^{19}$, y además iba a simbolizar su definitiva consolidación en el trono, por lo cual decidió colocar como tipo principal la escena de su coronación por el legado papal, que, como ya hemos dicho, se celebró en Bari el 4 de febrero de 1459.
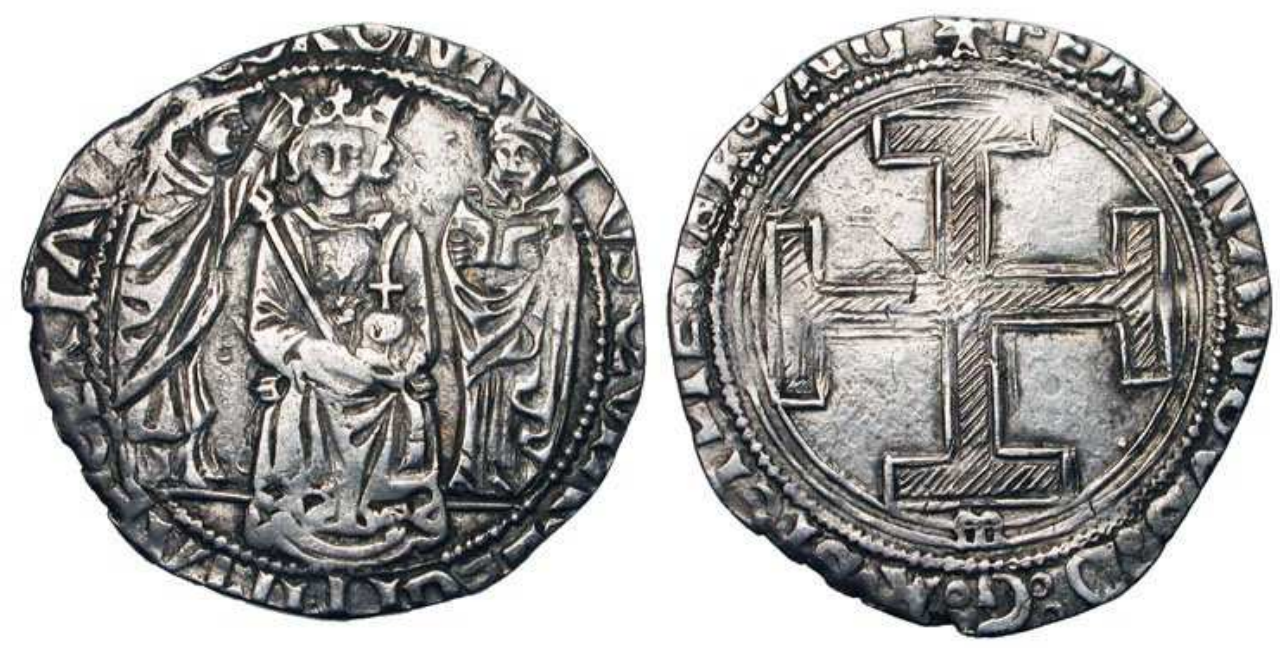

Fig. $\mathrm{n}^{\circ}$ 24. Travaini 958

Esta representación es única en toda la moneda medieval europea: hasta entonces nunca se había usado este tipo, pero en Nápoles tenía su razón de ser, porque la verdadera legitimación del monarca se hacía con la investidura papal y la posterior coronación, y esto precisamente era lo que quería resaltar Ferdinando. Por eso aparece sentado en el trono, con sus atributos (cetro y orbe), mientras el legado papal, cardenal Latino Orsini, le coloca la corona en la cabeza por mandato de la Santa Sede, siendo asistido en este acto por un representante del episcopado napolitano, en este caso, el arzobispo de Nápoles, Oliverio Carafa ${ }^{20}$. Para dar mayor fuerza propagandística a la escena, la leyenda que la rodea era: CORONATUS QUIA LEGITIME CERTAVIT, tomada de la segunda carta del apóstol San Pablo a Timoteo (II Tim 2.5) ("Y quien quiera que compite en el estadio no es coronado

desde la invasión de los árabes, Madrid, 1867, tomo II; Memmo CAGIATI, Le Monete del Reame delle Due Sicilie, Nápoles, 1911; y Philip GRIERSON \& Lucia TrAVAINI, Medieval European coinage: with a catalogue of the coins in the Fitzwilliam Museum, Cambridge. 14, Italy (III) (South Italy, Sicily, Sardinia), Cambridge, 1998.

${ }^{19}$ El carlino tenía 3,65 grs (88 en libra) y el coronato 4,01 grs. (80 en libra).

${ }^{20}$ Tradicionalmente se pensaba que este obispo era el arzobispo de Bari, lugar donde se celebró la coronación, pero no puede ser, porque en esta fecha esta sede estaba vacante, siendo administrada curiosamente por el cardenal Latino Orsini, legado papal de esta coronación. Según Conrad EUBEL, Hierarchia Catholica Medii Aevi, tomo II, Regensberg, 1914, Latino Orsini fue nombrado cardenal presbítero (con el título de San Juan y San Pablo) en la promoción del 20 de diciembre de 1448 por el papa Nicolás V, y tuvo la administración del arzobispado de Bari de 1454 a 1472; mientras que Oliverio Carafa fue nombrado arzobispo de Nápoles el 29 de diciembre de 1458. 
si no compite legítimamente") (Fig. 24), indicando claramente que la corona le corresponde legítimamente. En la otra cara de la moneda aparece la titulación real que ya hemos comentado, y como tipo la Cruz de Calabria (sobre campo de plata un cruz potenzada de sable), que fue el título (duque) que tuvo Ferdinando como heredero del reino, y con el que fue jurado por los barones en el parlamento pleno de 1443.

En los primeros años 80 los Anjou van a ir desapareciendo sin descendencia masculina: primero el gran rival de su padre, Renato (m.1480), y luego su sobrino Carlos de Maine (m.1481), que habían seguido reclamando sus derechos. La extinción de la Casa de Anjou hizo que sus estados y derechos pasaran a su heredero masculino más cercano, que era nada menos que el rey Luis XI de Francia (m.1483), cuyo hijo Carlos VIII (1483-1498) se encargará de volver a reivindicar militarmente sus derechos sobre Nápoles, pero a mediados de los 80 aún es un niño y todavía no es un peligro real.

Pero sí era un peligro la nobleza: en 1485 estalló en Nápoles lo que se conoció como la "Conjura de los Barones", cuyo origen hay que buscarlo en el descontento de la nobleza por la política del rey y su heredero, Alfonso, de aumentar el poder de la Corona a su costa. Por tal motivo buscaron el apoyo del nuevo papa, Inocencio VIII (1484-1492), que, a cambio de contraprestaciones para su familia, se lo dio. Las fuerzas papales ocuparon la estratégica ciudad de L'Aquila (donde se acuñó moneda a nombre del papa en 1485-86), y los rebeldes renovaron sus ataques, pero Ferdinando obtuvo el apoyo de la mayor parte de los estados italianos, y su hijo Alfonso llevó la dirección de la guerra y venció a todos sus enemigos, siendo el papa el primero en firmar la paz (11 de agosto de 1486), después de lo cual Alfonso entró triunfante en Nápoles (diciembre) y terminó de apresar a los rebeldes durante la primavera y verano siguientes.

Tras esta gran victoria y dura represión, el rey ordenó hacer unas nuevas monedas (1488), siendo una de ellas un nuevo tipo de "coronato", donde, manteniendo su retrato (rey vencedor), sustituye la Cruz de Calabria por la imagen del Arcángel San Miguel matando al dragón, que tiene varios significados: en primer lugar, San Miguel es el líder de las fuerzas celestiales (el bien), que mata a Satanás (el mal), una alegoría de cómo las fuerzas del rey han acabado con las de los rebeldes; además en Nápoles San Miguel tenía un gran centro de peregrinación en el Monte Gargano, en la costa Adriática, de renombre internacional, y era el patrón de la nueva orden de caballería fundada por el rey, la del Armiño (1465) ${ }^{22}$, por lo cual su elección como tipo queda clarificada, a lo que hay que añadir un cambio en la leyenda, ahora es IUSTA TUENDA, un aforismo que significa "lo justo debe ser protegido", de nuevo aludiendo a la legitimidad de luchar contra los que se levantan contra lo justo, en este caso su rey legítimo (Fig. 25).

\footnotetext{
${ }^{21}$ ZURITA, Anales...op.cit., libro XX, capítulo LXVI.

${ }^{22}$ Sobre esta orden, colocada bajo la protección del Arcángel San Miguel, ver D`Arcy Jonathan Dacre Boulton, The Knights of the Crown. The monarchical orders of Knighthood in Late Medieval Europe 1325-1520, New York, 2000, pp. 397-426.
} 

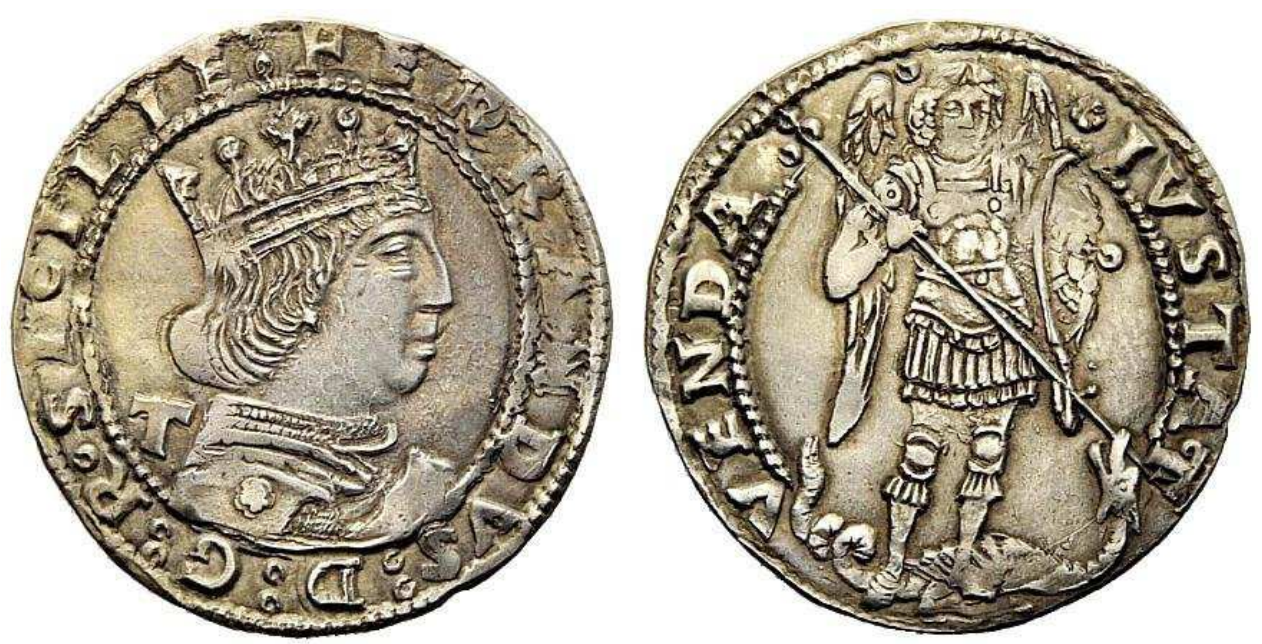

Fig. $n^{\circ} 25$. Travaini 1005

Como hemos visto, el reinado de Ferdinando fue muy agitado, y la última parte del mismo no iba a ser distinta: a principios de los años 90 el rey de Francia empezó a gobernar directamente, y expresó claramente su intención de reclamar el trono de Nápoles como heredero de los Anjou, y para ello empezó a realizar varias maniobras diplomáticas, mientras que Fernando el Católico, rey de Aragón, cada vez se interesaba más por los asuntos napolitanos y creaba un partido favorable a que este reino se integrara en la Corona de Aragón, desplazando a la rama bastarda de la familia ${ }^{23}$.

Todo el proceso se aceleró con la muerte de Inocencio VIII ${ }^{24}$ ( 25 de julio de 1492) y la elección como papa de Alejandro VI (1492-1503), el valenciano Rodrigo Borja, sobrino de Calixto III, y el candidato que menos deseaba el rey de Nápoles. Esta nueva situación llevó a Carlos VIII a acelerar sus proyectos, para lo cual necesitaba hacer la paz con Fernando el Católico, que fue firmada el 8 de enero de 1493 (Tratado de Barcelona): por este acuerdo Carlos devolvía los condados de Rosellón y Cerdeña a Fernando, y se restablecía la buena vecindad entre ambos, prohibiendo la ayuda a cualquier enemigo de las partes firmantes, exceptuando al papa. La entrega de los condados se realizó en septiembre de 1493, con lo cual Carlos VIII se había asegurado su frontera sur.

Mientras el francés seguía maniobrando en Italia, el papa impulsó una liga para preservar la paz en Italia y defenderse de los turcos (25 de abril de 1493), formada

\footnotetext{
${ }^{23}$ Hay que recordar que Juana, hermana del rey Fernando, se había casado con el rey Ferdinando, siendo por tanto reina de Nápoles, y era el mejor agente de su hermano en el reino, informándole de todo lo que allí ocurría y trabajando a favor de sus intereses.

${ }^{24}$ El rey Ferdinando de Nápoles había conseguido de este papa nuevas seguridades para su reino: primero una resolución de los conflictos bilaterales (22 de enero de 1492), y luego, poco antes de su muerte, una Bula en la que declaraba que al hijo de Alfonso $\mathrm{V}$ y a sus descendientes varones por línea de primogenitura les correspondía la legítima posesión de la corona de Nápoles (4 de junio de 1492), siendo una copia de la misma enviada a España (AGS., Patronato Real, leg.41, fol.17), tal vez como advertencia a la política intervencionista de Fernando el Católico, que reclamaba ser el heredero legítimo de Alfonso V. Ver Luis SUAREZ FERnANDEZ, Los Reyes Católicos, tomo III: El Tiempo de la Guerra de Granada, pp. 294-310; tomo IV. EL Camino hacia Europa, Madrid, 1990, pp. 11-29.
} 
por los Estados Pontificios, Milán y Venecia, invitando a Carlos VIII a entrar en ella. Este aprovechó su posición para pedir oficialmente al papa la investidura del reino de Nápoles (agosto) como heredero de los Anjou, pero inesperadamente Alejandro VI se negó a ello, de momento.Pensando que había conseguido detener las ambiciones francesas, el rey Ferdinando murió el 25 de enero de $1494^{25}$.

Su hijo Alfonso tomó inmediatamente el poder y pidió al papa la investidura del reino, y Alejandro VI, tras conseguir importantes ventajas para su familia, se la concedió, procediéndose a la preceptiva coronación el día 8 de mayo de 1494. El papa mandó como legado al cardenal Juan de Borja, arzobispo de Monreale, que fue el encargado de oficiar la ceremonia, que se realizó con gran magnificencia y sin reparar en gastos, ya que con ella se mostraba la legitimidad del monarca al pueblo y a los enemigos del rey ${ }^{26}$.
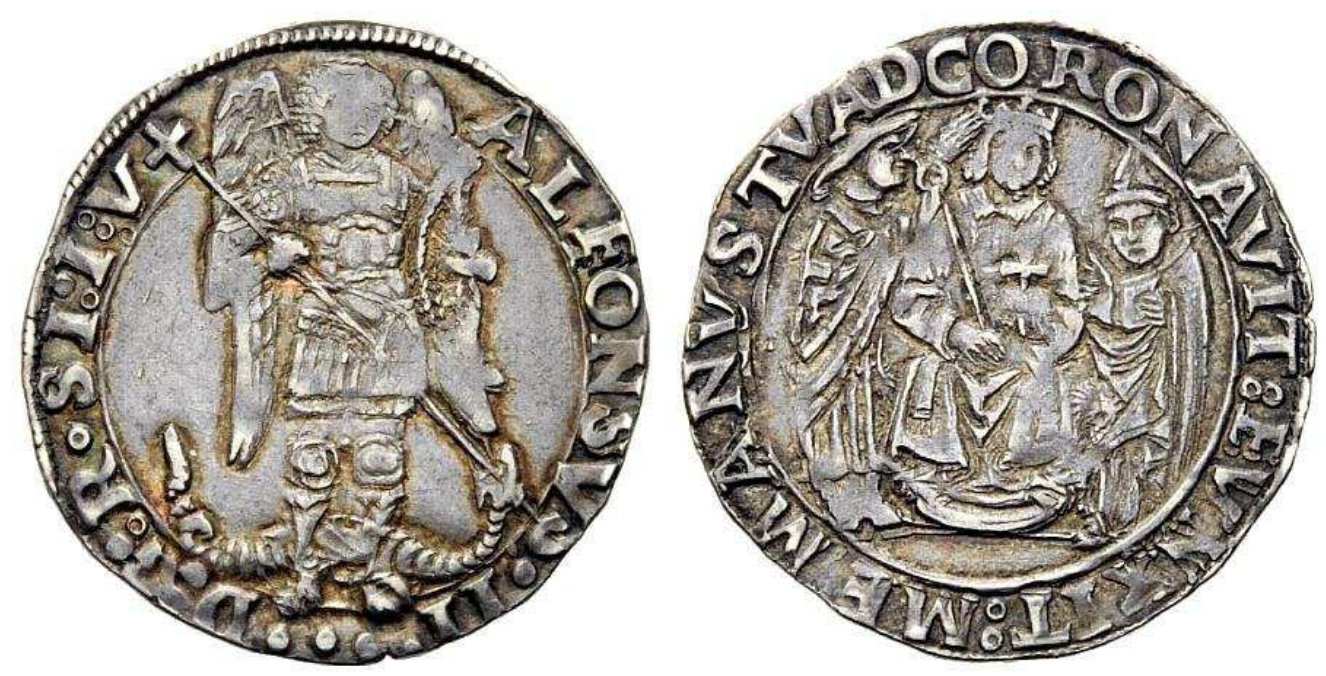

Fig. $n^{\circ}$ 26. Travaini 1034

Sus primeras acuñaciones avalan esta utilización propagandística: Alfonso II ordenó acuñar ducados de oro iguales a los que hizo su padre, es decir, con el retrato y el escudo heráldico, muestra de sus derechos dinásticos; y también un "coronato" de plata, con la misma escena de la coronación que utilizó su padre en las piezas de 1462, aunque esta vez cambian los personajes que la interpretan, siendo el cardenal legado, Juan de Borja, y el representante del episcopado, el arzobispo de Nápoles, Alessandro Carafa ${ }^{27}$; además la leyenda CORONAVIT ET UNXIT ME MANUS TUA DOMINE ("Oh Señor me has coronado y ungido por

\footnotetext{
${ }^{25}$ Jerónimo ZURITA, Historia del rey Don Hernando el Católico: de las empresas y ligas de Italia. Zaragoza, 1580 (Edición de Angel Canellas López, Zaragoza, 1989), libro I, capítulos XVII-XVIII, habla del carácter del difunto y de su heredero, así como de la complicada situación internacional del reino de Nápoles. Esta obra de Zurita es la mejor para entender los complicados acontecimientos italianos de la época, y es de consulta obligada por la claridad de su exposición.

${ }^{26}$ ZURITA, Historia..., libro I, capítulo XXX.

${ }^{27}$ Según Conrad Eubel, Hierarchia Catholica Medii Aevi, tomo II, Regensberg, 1914, Juan de Borja, arzobispo de Monreale (en Sicilia), fue nombrado cardenal presbítero (con el título de Santa Susana) en la promoción del 31 de agosto de 1492 por el papa Alejandro VI; mientras que Alesandro Carafa fue nombrado arzobispo de Nápoles el 20 de septiembre de 1484.
} 
tu mano") es un ejemplo de doble legitimación, una la divina como ungido del Señor, y otra la feudal, ya que el papa como soberano del reino le ha otorgado solemnemente la investidura. En la otra cara de la moneda mantiene el último tipo de su padre, es decir, el Arcángel San Miguel matando al dragón, con el mismo significado, ya que la derrota de los Barones fue obra personal de Alfonso, que mandaba el ejército y dirigió la posterior represión, que todavía era muy recordada en el reino (Fig. 26).

Frente a esta aparente seguridad de la posición de Alfonso II se alzó Carlos VIII, que desde la muerte de Ferdinando dejó claras sus intenciones, volviendo a pedir al papa la investidura del reino de Nápoles (febrero y marzo de 1494), y, como Alejandro VI volvió a excusarse alegando la complejidad del problema y la necesidad de un estudio detallado del mismo, el francés puso en marcha su maquinaria diplomática y militar, que iba a socavar el poder del papa, aliándose con cardenales afectos (como Giuliano della Rovere, futuro Julio II) y poderosas familias de los Estados Pontificios (los Colonna), por lo cual el papa tomó la decisión de apoyar a Alfonso de Nápoles y coronarle, como ya hemos visto, formando una alianza Roma-Nápoles-Florencia contra el posible ataque de Francia.

Carlos atravesó los Alpes en septiembre de 1494 y derrotó a las fuerzas de sus enemigos, llegando a Pavía el 14 de octubre, y antes de finalizar el mes entraba en Florencia como libertador (un movimiento popular había derribado a los Médicis), el 27 de noviembre ocupaba Viterbo y el 27 de diciembre entraba en Roma. Ante estos hechos Alfonso II decidió abdicar (21 de enero de 1495) en su hijo, el joven Ferrante II, que decidió hacer frente a los franceses, pero una rebelión interna debilitó su posición: Capua cayó el 18 de febrero de 1495 y Nápoles el día 22, mientras Ferrante se retiraba a Sicilia.

Carlos VIII había vencido, se autocoronó el 12 de mayo (sin la necesaria presencia del legado papal), pero ahora Fernando el Católico iba a entrar en escena $^{28}$, primero apoyando a su pariente Ferrante II, que conseguiría recuperar pronto su trono $(1496)^{29}$, y luego usando la diplomacia para pactar con Luis XII de Francia el reparto del territorio ${ }^{30}$, y por fin, gracias a las victorias del Gran Capitán,

\footnotetext{
${ }^{28}$ El 31 de marzo de 1495 se formó una Liga integrada por el papa, el emperador Maximiliano, Venecia, Milán y el propio Fernando el Católico, cuyo objetivo era la defensa mutua contra cualquier agresión, que, sin decirlo expresamente, era la expedición francesa a Italia.

${ }^{29} \mathrm{El}$ virrey francés, duque de Montpensier, se rindió el 27 de junio de 1496 ante las fuerzas del rey Ferrante comandadas por el castellano Gonzalo Fernández de Córdoba, pero desgraciadamente el joven rey murió pronto (7 de octubre de 1496) y fue sucedido por su tío Federico III (Fadrique), cuyas relaciones con Fernando el Católico era muy malas. Ver SuAREZ FERnANDEZ, Los Reyes Católicos. El camino hacia Europa, op.cit., pp. 61-89.

${ }^{30}$ Tratado de Granada (11 de noviembre de 1500), por el cual Luis XII se convertía en rey de Nápoles, ocupando la capital más la Tierra de Labor y los Abruzzos, mientras Fernando anexionaba a su reino siciliano las provincias de Calabria y Apulia. Cada monarca debía ocupar militarmente su parte y se ayudarían contra quien se opusiera a ellos; además el papa Alejandro VI confirmó el acuerdo y por una bula de 25 de junio de 1501 otorgó a cada monarca la investidura formal de los territorios que debían ocupar, y en julio los ejércitos de Luis y Fernando comenzaron la ocupación que se realizó sin excesivos problemas, y Federico III abdicó el 26 de septiembre de 1501.
} 
convertirse en el único soberano de Nápoles $(1504)^{31}$. Pero eso ya está dentro del gran enfrentamiento hispano-francés en todos los frentes europeos que marcarían la historia del siglo XVI y no concierne a este trabajo.

\section{Conclusiones}

Como hemos visto el Arcángel San Miguel se fue convirtiendo en uno de los más importantes referentes iconográficos del cristianismo durante la época medieval, dado su importante papel en varios importantes campos teológicos, pero para el pueblo fue además un gran sanador, y así fue considerado desde los inicios del cristianismo en oriente, para unos siglos después adquirir preponderancia su papel militar, relacionado con el concepto de caballería, tanto en oriente como en occidente.

Y esta importancia se va a ver en las monedas, un documento oficial de primer orden: así lo hemos visto en Bizancio (siglos XI-XIII) y luego en Occidente, donde además se quiere utilizar su figura en la lucha entre la Monarquía y los Barones, donde la primera quiere asemejarse al poder legítimo avalado por la divinidad, llevando cualquier rebelión contra ella a identificarla con la de Satanás y los ángeles caídos, por lo cual la figura victoriosa de San Miguel es un arma propagandística de primer orden en momentos de rebeliones. Tal fenómeno se ve en Francia, Inglaterra y Nápoles, donde los monarcas van a optar por apoyar esta tipología en sus monedas como medio de defender sus intereses y su poder frente a las pretensiones de la nobleza, abriendo así el camino para la consolidación de las grandes monarquías occidentales, que basarán su poder en un creciente autoritarismo monárquico.

\section{Fuentes y Bibliografía}

Bellinguer, Alfred, Grierson, Philip y Hendy, Michael F., Catalogue of the Byzantine Coins in the Dumbarton Oaks Collection and in the Whittemore Collection (DOC), Washington, 1993.

Blanchet, Adrien \& DiEUdOnNE, Adolphe Edmond, Manuel de Numismatique Française, Paris, 1912-1936.

Boulton, D’Arcy Jonathan Dacre, The Knights of the Crown. The monarchical orders of Knighthood in Late Medieval Europe 1325-1520, New York, 2000.

BRUnN, Patrick M., The Roman Imperial Coinage. Vol. VII Constantine and Licinius, Londres, 1966.

BRunN, Patrick M., "The Christian Signs on the Coins of Constantine", Arctos; acta philologica fennica, vol.3 (1962).

BRUNN, Patrick M., “The Victorious Signs of Constantine: A Reappraisal." The Numismatic Chronicle 157 (1997).

\footnotetext{
${ }^{31}$ En 1502 se rompieron las hostilidades entre Luis XII y Fernando el Católico, logrando Gonzalo Fernández de Córdoba en 1503 las grandes victorias de Cerignola y Garellano, que llevaron a la ocupación total del Reino en los primeros meses de 1504.
} 
CAgiati, Memmo, Le Monete del Reame delle Due Sicilie, Nápoles, 1911.

Chapman, C., Michel Paléologue, restaurateur de l'Empire byzantin, París, 1926, pp. 166-168.

CIANI, Louis, Les monnaies royales françaises de Hugues Capet à Louis XVI, Paris, 1926.

Millares CARlo, Agustín, Tratado de Paleografía Española, Madrid, 1983.

CUTLER, A., Transfigurations : Studies in the Dynamics of Byzantine Iconography, Pennsylvania-Londres, 1975.

DunNING, Mark, "First Christian Symbols on Roman Imperial Coins" The Celator 17, (December 2003).

EuBEL, Conrad, Hierarchia Catholica Medii Aevi, Regensberg, 1914.

FrANCISCO Olmos, José María de, "La Manus Dei en la Moneda Bizantina (siglos VIII-XII)", Crónica Numismática no 176 (diciembre de 2005).

GrIERSON, Philip \& TrAVAINI, Lucia, Medieval European coinage: with a catalogue of the coins in the Fitzwilliam Museum, Cambridge. 14, Italy (III) (South Italy, Sicily, Sardinia), Cambridge, 1998.

HEISS, Aloiss, Descripción general de las monedas hispanocristianas desde la invasión de los árabes, Madrid, 1867.

KENT, J.P.C., The Roman Imperial Coinage. Vol. VIII. The Family of Constantine, Londres, 1981.

KIERNAN, Philip, "A Study on the Religious Propaganda of Ancient Coin Reverse Types, A.D. 313-337”, The Journal of the Classical \& Medieval Numismatic Society 2 (June 2001).

LONGTIN, Rachelle "Constantine and Christianity: The Numismatic Evidence", The Journal of the Classical \& Medieval Numismatic Society 1 (September 2000).

PONTIERI, Ernesto, Per la Storia del Regno di Ferrante I d'Aragona re di Napoli, Nápoles, 1968.

SEABy, Peter \& PurveY, Frank, Coins of England and the United Kingdom, Londres, 1980.

SEAR, David R., Byzantine Coins and their values, Londres, 2000.

SuAREZ FERnANDEZ, Luis, Los Reyes Católicos, Madrid, 1990.

TALBOT, A.M.Maffry, "The Restoration of Constantinople under Michael VIII", Dumbarton Oaks Papers, 47 (1993).

ZuRITA, Jerónimo, Anales de la Corona de Aragón. Zaragoza, 1592 (Ed. de Angel Canellas, Zaragoza, 1967).

ZURITA, Jerónimo, Historia del rey Don Hernando el Católico: de las empresas y ligas de Italia. Zaragoza, 1580 (Edición de Angel Canellas López, Zaragoza, 1989). 


\section{Abreviaturas}

DOC: Dumbarton Oaks Collection

Bellinguer, Alfred, GrIERson, Philip y Hendy, Michael F., Catalogue of the Byzantine Coins in the Dumbarton Oaks Collection and in the Whittemore Collection, Washington, 1993.

RIC: The Roman Imperial Coinage

BRUnN, Patrick M., The Roman Imperial Coinage. Vol. VII. Constantine and Licinius, Londres, 1966.

KEnT, J.P.C., The Roman Imperial Coinage. Vol. VIII. The Family of Constantine, Londres, 1981. 